\title{
Identifying Altruism in the Laboratory
}

\author{
by
}

Glenn W. Harrison and Laurie T. Johnson †

May 2004

\begin{abstract}
Is it possible to measure the extent of altruism in a controlled laboratory environment? Recent attempts to measure altruism towards other players or charities suffer from two potential confounds. One is the fact that the act of giving is typically correlated with extracting surplus from the experimenter. Thus, what could appear to be altruistic acts might just be a desire to make sure that the experimenter ends up with as little as possible. Or, on the other hand, revealed altruism might be understating true altruism if subjects value money being left on the (experimenter's) table. The other general confound is that subject preferences with respect to altruism are likely to be heterogeneous across subjects. This can confound inferences because the sample sizes typically employed in experiments are insufficient to ensure that randomization to treatment will correct for differences in treatment behavior due solely to differences in sample composition. We illustrate each of these points with simple laboratory experiments that derive from popular recent designs. We find that there is a significant effect from each confound, and that the results are surprising. Depending on the context, revealed altruism might overstate or understate true altruism if one fails to correct for "as if" acts of altruism being negatively correlated with experimenter surplus. Furthermore, unconditional measures of altruism can be qualitatively misleading, due to the unusually variable nature of the propensity to undertake acts of altruism. Fortunately, this variable propensity appears to be associated with readily observable characteristics of individuals, so that one can correct for differences in sample composition across treatments. We conclude that altruism does exist, but that it cannot be identified independently of the circumstances of the task.
\end{abstract}

$\dagger$ Department of Economics, College of Business Administration, University of Central Florida (Harrison), and Department of Economics, University of Denver (Johnson). E-mail contacts: gharrison@bus.ucf.edu and lauriejo@du.edu. We are grateful to Philip Grossman, Andreas Ortmann and Elisabet Rutström for comments. Supporting data and instructions are stored at the ExLab Experimental Social Sciences Digital Library at http:/ / exlab.bus.ucf.edu in project "Identifying Altruism in the Laboratory." 
Is it possible to measure the extent of altruism in a controlled laboratory environment?

Recent attempts to measure altruism ${ }^{1}$ towards other players or charities suffer from two potential confounds. We propose a design that controls for those confounds, and then test to see if they influence the extent of altruistic responses. We find that they dramatically change the measured extent of altruism, in some cases increasing it and in other cases decreasing it. These potential confounds are more general than the context considered here, in the sense that they could be a factor in many other experimental settings. They are also likely a priori to be highly contextual, cautioning against generalizations about the propensity for altruistic behavior.

The first potential confound arises from the fact that the act of giving is often correlated with extracting surplus from the experimenter. Thus, what could appear to be altruistic acts might just be a desire to make sure that the experimenter ends up with as little as possible. Or, on the other hand, revealed altruism might be understating true altruism if subjects value money being left on the (experimenter's) table. There is a budget constraint that requires that the money paid to the subjects come from somewhere else, and the choice of a particular "somewhere else" can matter for elicited preferences.

The other potential confound is that subject preferences with respect to altruism tend to be

\footnotetext{
${ }^{1}$ The recent experimental literature tends to define altruism as distinct from notions of fairness or reciprocity. This is unfortunate. Without too much exegesis, it is apparent that altruism is a more general notion that subsumes the others. In fact, the word itself has an interesting and surprisingly recent history, first gaining use in English around 1853. The Oxford English Dictionary (Second Edition) defines it as "devotion to the welfare of others, regard for others, as a principle of action; opposed to egoism or selfishness." It comes directly from the French word altruisme, which in turn was formed by Auguste Comte (1798-1857), a French philosopher regarded as the founder of sociology. Comte was a strong opponent of the view that one could usefully distinguish economic and social aspects of life, and was critical of the writings of many economists for apparently doing so. Comte based the French word on the Italian altrui, which means "of or to others, what is another's." Thus the task of identifying altruistic behavior is separate from the task of identifying possible motives for altruism, unless assumptions about the structure of those motives are used to help in the identification inference. We prefer a more agnostic approach, which also implies that we have nothing to say about those motives. In fact, we believe it is premature to start drawing firm conclusions about those motives on the basis of experimental data collected to date. For this reason, and following Andreoni and Miller [2002], we do not attempt to differentiate "pure altruism" from "impure altruism" as these terms have been defined by Andreoni [1990].
} 
heterogeneous. Clearly they are subjective, but this is likely to be one of those choices that could depend more than usually on the personal characteristics of the individual and the context of the act itself. This is a confound because the sample sizes often employed in experiments are not sufficient to ensure that randomization to treatment will correct for differences in treatment behavior due solely to differences in sample composition. Thus inferences about treatments that fail to condition on sample differences might be misleading.

We illustrate each of these points with some simple laboratory experiments that derive from popular designs. We find that there is a significant effect from each confound, and that the results are surprising (to us, at least). Depending on the context, revealed altruism might overstate or understate true altruism if one fails to correct for "as if" acts of altruism being negatively correlated with experimenter surplus. ${ }^{2}$ Furthermore, unconditional measures of altruism can be qualitatively misleading, due to the unusually variable nature of the propensity to undertake acts of altruism. Fortunately, this variable propensity appears to be associated with readily observable characteristics of individuals, so that one can correct for differences in sample composition across treatments if one collects and statistically controls for that heterogeneity.

In section 1 we define the basic experimental games used previously, and then discuss the problem of interpreting behavior from them. In section 2 we design experiments that allow us to control for the potential confounds, and in sections 3 and 4 report laboratory experiments using that design.

We conclude that altruism can be identified, but that it is clearly contextual and varies from individual to individual. More important, we identify some general confounds that will have to be

\footnotetext{
2 In a sense to become clear, these are understatements or overstatements relative to the usual baselines approach employed in these experiments. Since the propensity to undertake altruistic acts is highly contextual, also in ways to become clear, we do not believe it is useful to talk about some universal quantitative propensity to be altruistic.
} 
addressed in all experiments that presume to identify altruism, as well as in other experiments. ${ }^{3}$

\section{Gift-Giving Games and Their Interpretation}

\section{A. The Dictator Game}

Most of the gift-giving games used in experiments take the form of modifications of the Dictator game, introduced as such by Forsythe, Horowitz, Savin and Sefton [1994]. In that game two players are paired at random. Each receives some initial endowment, and one player can pass any fraction of his endowment to the other player. The player receiving the gift has no response to make in a game-theoretic sense, so there is no element of strategy in the behavior of the first player. Extensions of Dictator that allow for responses of the second player include the Ultimatum game (where the second player can accept the offer or reject the proposal, in which case neither player receives anything) and the Trust game (where the second player decides how much of the gift, after it has been scaled up by some fixed ratio, to send back to the first player).

The results from Dictator are that players often send a positive fraction of their initial endowment to the other player, which is inconsistent with the first player having preferences defined solely over his own payoffs. Thus, passing behavior under Dictator is correctly viewed as evidence

\footnotetext{
${ }^{3}$ We agree with the general position of Charness and Rabin [2002; p.818]: “A major motivation for our research was a concern about pervasive and fundamental confounds in the experimental games that have inspired recent social-preferences models. Most notably, papers presenting difference-aversion models have argued that Pareto-damaging behavior - such as rejecting unfair offers in ultimatum games, where subjects lower both their own and others' payoffs - an be explained by an intrinsic preference to minimize differences in payoffs. But this explanation is almost universally confounded in two ways: First, opportunities for inequality-reducing Pareto-damaging behavior arise in these games solely when a clear motivation for retaliation is aroused. Second, the only plausible Pareto-damaging behavior permitted is to reduce inequality. Difference aversion has also been used to explain helpful sacrifice - such as cooperation in prisoner's dilemmas - as a taste for helping those with lower payoffs. But here again two confounds are nearly universal: the games studied only allow efficient helpful sacrifice that decreases inequality, and only when a motive for retaliation is not aroused. All of these confounds mean that the tight fit of these models may merely reflect the fact that in many of the games studied their predictions happen both to be the only way that subjects can depart from self-interest, and to be the same as the predictions of reciprocity." Cox [2004] makes a similarly general point about the lack of attention to potential confounds in the interpretation of Trust games.
} 
that some subjects have some "other-regarding preferences" in the context of the traditional laboratory experiment.

The importance of context has been examined in several experiments, and the evidence suggests that framing does matter. For example, Hoffman, McCabe, Shachat and Smith [1994] demonstrate that the seemingly innocuous use of the word "divide" in bargaining game instructions, and the use of random initial endowments, could lead to deviations from theoretical predictions. Similarly, the experiments of Cherry, Frykblom and Shogren [2002] included a treatment in which subjects earned their initial bargaining stake as the result of a non-trivial quiz. Those subjects that did better in the quiz earned $\$ 40$, and the others earned $\$ 10$. In the control experiment subjects were simply endowed with these different amounts. The responses were striking: offers to the other player were much less generous when subjects had earned the initial stake, whether or not the responses were "double-blind." There are other examples of the effects of framing and context in related settings, such as Andreoni [1995], Sonnemans, Schram and Offerman [1998] and Small and Loewenstein [2003], but the implication is that one has to take it into account in experiments. We therefore echo the conclusion of Eckel and Grossman [1996b; p.188ff.] in a similar context:

It is received wisdom in experimental economics that abstraction is important. Experimental procedures should be as context-free as possible, and the interaction among subjects should be carefully limited by the rules of the experiment to ensure that they are playing the game we intend them to play. For tests of economic theory, these procedural restrictions are critical. As experimenters, we aspire to instructions that most closely mimic the environments implicit in the theory, which is inevitably a mathematic abstraction of an economic situation. We are careful not to contaminate our tests by unnecessary context. But it is also possible to use experimental methodology to explore the importance and consequence of context. Economists are becoming increasingly aware that social and psychological factors can only be introduced by abandoning, at least to some extent, abstraction. This may be particularly true for the investigation of other-regarding behavior in the economic arena. 


\section{B. Aversion to Inefficiency}

We focus on one generic aspect of the context or frame of the standard gift-giving task, which we call “inefficiency aversion.” In most of the gift-giving experiments, any monies passed by the first player to the second are scaled up by the experimenter. Thus $\$ 1$ sent from the first player to the second player (or charity) might become $\$ 3$ in the hands of the second player (or charity). We examine specific instances of these games below.

This design feature became explicit with Eckel and Grossman [1996a][1996b]. They correctly observed that there is at least one important confound making comparisons of Ultimatum bargaining outcomes and Dictator outcomes problematic: the relative price of fairness. Specifically, in Ultimatum the foregone expected earnings of holding on to money is higher than in Dictator, since the more the subject holds on to the more likely is it that the other player will reject the proposal. ${ }^{4}$ Since this confound depends on the subjective expectations of the players and risk attitudes, it is not well controlled for, even if we do know that it can only be higher in Ultimatum than in Dictator. ${ }^{5}$ Hence they proposed explicitly controlling for the relative price of fairness with the gift-giving designs now popular.

Consider a game in which there are two players, rather than one player and a charity. If the subject being asked to make the allocation places no value on the monies retained by the experimenter at the end of the game, but does place a positive value on the monies being allocated to himself or the other player, then such players would like to see those monies allocated away from the experimenter. More generally, if the subject just places a higher value (in terms of his own subjective evaluations) on monies being in the hands of either subject rather than the experimenter,

\footnotetext{
${ }^{4}$ It is empirically more likely: the subgame-perfect Nash Equilibrium predicts that it is equally unlikely.

${ }^{5}$ The fact that it is higher could actually be an attraction to risk-lovers, of course.
} 
then there is a motive to pass money to the other player. To take an extreme example, what if the experimenter announces that he brought $\$ 3,000$ to the session beyond the fixed show-up fees, since there were 10 pairs and he might have to pay out up to $\$ 3,000$, but that he planned on donating the money he retained at the end to the National Rifle Association or the American Civil Liberties Union. ${ }^{6}$ Subjects have a wide range of attitudes toward these organizations, running the gamut from love to hate. Quite apart from other-regarding preferences towards the other player, and any other confounds, ${ }^{7}$ this planned disposition of any funds not retained by the subjects would be expected to influence behavior within the game, with at least some subjects wanting to minimize the residual donations by the experimenter. ${ }^{8}$ The way to do that, in fact the only way given the structure of this game, is to pass money to the other player and behave "as if" altruistic."

Subjects may or may not be averse to inefficiency as we have defined it. Just as the general term "risk aversion" allows for risk loving behavior as well as risk neutrality, we view the notion of inefficiency aversion as including cases in which the subjects prefer to see monies left in the hands of the experimenters or could care less. We presume that subjects want to maximize surplus

\footnotetext{
${ }^{6}$ The NRA nominally supports the Second Amendment of the United States Constitution, which provides that individuals have a right to bear arms; see http://www.nra.org/. The ACLU supports the Constitution more generally; see http://www.aclu.org/. Each has some vocal critics in the U.S. media, which presumably indicates that some fraction of the population are also critical of them.

${ }^{7}$ In the context of Trust games, for example, there is also a potential confound from uncontrolled attitudes to risk.

${ }^{8}$ Since these are public organizations that the subjects could send their earnings to, responses will be censored for those subjects that are planning to contribute to the organization after the experiment.

9 Engelmann and Strobel [2004] make the same point, and design experiments to identify the importance of the aversion to inefficiency relative to other motives. Unfortunately, virtually all of their treatments consider situations in which the decision-maker is indifferent between the choices of interest if motivated solely by own-payoff. The exceptions are their treatments $\mathrm{Nx}, \mathrm{Ny}$ and $\mathrm{Nyi}$, and in treatment $\mathrm{Nx}$ the allocation that maximizes own-payoff and group payoff are the same. In fact, only 55 of their 409 observations are inconsistent with subjects choosing an allocation that maximizes their own payoff, so any evidence for "altruism" in the remaining 354 observations was completely costless to the subject. In their treatment $\mathrm{Ny}$ (Nyi) subjects faced a multiplier of 4 (9), in the sense that every currency unit they gave up generated 4 (9) currency units for the other two players together. In these two treatments there was considerable evidence of (costly) altruism that cannot otherwise be explained by self-interest. Others to point explicitly to the role of inefficiency aversion include Frank [1998], Kritikos and Bolle [2001], Charness and Rabin [2002] and Cox [2004].
} 
extracted from the experimenter on behalf of subjects as a whole, but stress that this is just a presumption that has to be evaluated in the context of each experiment.

Although it might be tempting to call this "just another framing effect," we believe it is also more fundamental from a traditional perspective. The budget constraint binding the experimenter implies a task representation to subjects, if we rule out deception, and that task representation can rationally influence behavior. Consider the context of an experimenter in a poor country that is visiting from a rich country. Whittington [2002; p.356ff.] discusses the difficulties faced when deciding how much one should pay a survey enumerator in a poor, less developed country, suggesting as a rule of thumb that they be paid no more than 5 to 10 times the local wage. His experiences could almost count as a field experiment itself:

But these general guidelines are no substitute for a high level of political sensitivity in settling on and/or negotiating monetary compensation for enumerators. Particularly in situations where applicants for positions as enumerators have no experience working with foreign donors or international agencies, their expectations about wages can be very high. Potential enumerators may, for example, expect to be paid international wage rates.

I have had [...] experiences in which I got off on the wrong foot because of initial negotiations over wages. Both were in rural situations in which local wage rates for unskilled labor were exceedingly low (less than US\$1 per day). Once in Haiti I literally had a group of potential enumerators react violently to a proposal I made for wage rates that I considered very generous. I managed to leave, but not before a crowd of potential enumerators attacked my car.

Think of his initial proposal as a "generous offer" in a field Ultimatum bargaining game as he represented the pie, and these attacks as rejections from subjects that represented the pie differently. This is just a difference in expectations, which are known from controlled laboratory experiments ${ }^{10}$ to have a dramatic and predictable effect in Ultimatum, but it derived from the task representation. Thinking about the experimenter's budget constraint can drive a myriad of possible representations

${ }^{10}$ Harrison and McCabe [1996]. 
in the Dictator game, even in the absence of frames that might push subjects to favor one representation over another. At the very least, control over task representation might be lost.

The possibility that the disbursement of the residual claim in an experiment might affect responses is clearly identified by Levine [1998; p.598]. Assuming no role for the beliefs of player $i$ about the altruism of the other player in a two-person game, ${ }^{11}$ he follows Ledyard [1995] and proposes a utility function for player $i$ as:

$$
v_{i}=u_{i}+a_{i} \times u_{j}
$$

where $u_{i}$ is the direct utility of player $i$ from his own monetary payoff, and $a_{i} \in(-1,1)$ is a coefficient of altruism. If $a_{i}$ is positive the player is said to be altruistic, if it is zero he is selfish, and if it is negative he is said to be spiteful. With this background, he then has an unusually careful discussion of how one interprets experimental payoffs in terms of utility, a critical issue for any attempt to identify altruism:

In studying experiments, we will identify the participants' utility with their monetary income from the experiment. [...] It is important to note, however, that the money that is not received by the participants reverts to the experimenter, and there is no reason for the subjects to feel differently about the experimenter than the other subjects. However, it does not seem sensible to identify the utility of the experimenter with the amount of money that reverts to him. Instead, we will assume that the marginal utility of the experimenter for money that is not disbursed to the subjects is zero, so that in effect, from the subject's point of view, the money is thrown away, and the altruism coefficient $a_{i}$ does not matter. Notice that it is possible to design experiments to control more carefully for the effect of money that is not received by the subjects. Rather than having the money revert to the experimenter, one subject can be chosen to be the residual claimant, with all money not disbursed to the subjects being given to the residual claimant, who does not otherwise participate in the experiment. In this case, the utility of money not going to the participants other than the residual claimant can also be identified with money income, and the residual claimant should be viewed by the other subjects as having

${ }^{11}$ Levine [1998] does in fact allow for more than two players as well as a role for the altruism for the other players in defining the utility of player $i$, arguing that this is needed to explain behavior in strategic games such as Ultimatum. In his notation, the case we consider is when $\lambda=0$. It is noteworthy that although the altruism coefficient is subject-specific, this model assumes that the regard player's have for the altruism of other players is the same for all players. 
the population mean value of $a_{i}$. According to the theory, this should have an effect on the outcome of the experiment.

Our experiments can be seen as tests of this hypothesis.

\section{Giving to Others}

Building on Eckel and Grossman [1996a][1996b][1998], Andreoni and Miller [2002]

implement a simple experiment to elicit altruistic preferences. Our design is based on their

experiment. The instructions for the main task in our version are brief:

In this experiment you are asked to make a series of choices about how to divide points between yourself and one other subject in the room. You are the other subject will be paired randomly and you will not be told each other's identity.

As you divide the points, you and the other subject will each earn money. Every point that you earn will be worth 10, 20 or 30 cents, depending on the choice. For example, if you earn 58 points you will make $\$ 5.80$ in the experiment if your points are worth 10 cents for that choice. Similarly for the earnings of the other player.

Each choice you make is similar to the following:

Divide 50 points: Hold (a) \$0.10 each, and Pass (a) $\$ 0.20$ each.

In this choice you must divide 50 points. You can keep all of the points, keep some and pass some, or pass all of the points. In this example, you will receive 10 cents for every point you hold, and the other player will receive 20 cents for every point you pass. For example, if you hold 50 and pass 0 points, you will receive $50 \times \$ 0.10=\$ 5.00$, and the other player will receive no points and $\$ 0$. If you hold 0 and pass 50 points, you will receive no point and $\$ 0$, and the other player will receive $50 \times$ $\$ 0.20=\$ 10.00$. However, you could choose any number between 0 and 50 to hold. For instance, you could choose to hold 29 tokens and pass 21 . In this case you would earn 29 points, or $29 \times$ $\$ 0.10=\$ 2.90$, and the other subject would receive $21 \times \$ 0.20=\$ 4.20$.

Here is another example:

Divide 50 points: Hold (a) \$0.30 each, and Pass (a) \$0.10 each.

In this example every point you hold earns you 30 cents, and every point you pass earns the other subject 10 cents.

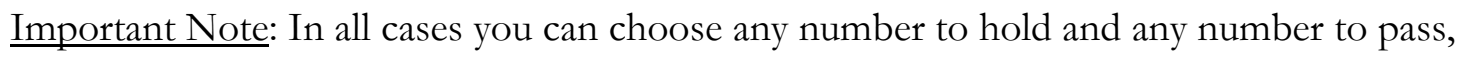


but the number of points you hold plus the number of points you pass must equal the total number of points to divide.

Please do not talk. Are there any questions?

The actual tasks given to subjects by Andreoni and Miller [2002] were randomized across subjects in terms of order, but consisted of the following in most of their experiments:

1. Divide 75 points: Hold

2. Divide 40 points: Hold

3. Divide 75 points: Hold

4. Divide 60 points: Hold

5. Divide 40 points: Hold

6. Divide 60 points: Hold

7. Divide 100 points: Hold

8. Divide 60 points: Hold

9. Divide 80 points: Hold

10. Divide 40 points: Hold

11. Divide 40 points: Hold (a) \$0.10 each, and Pass (a) $\$ 0.10$ each, and Pass (a) $\$ 0.20$ each, and Pass (a) $\$ 0.10$ each, and Pass (a) \$0.30 each, and Pass (a) \$0.10 each, and Pass (a) \$0.10 each, and Pass @ \$0.20 each, and Pass (a) $\$ 0.10$ each, and Pass @ \$0.40 each, and Pass @ $\$ 0.10$ each, and Pass (a) $\$ 0.20$ each. (a) $\$ 0.30$ each. (a) $\$ 0.10$ each. (a) $\$ 0.20$ each. @ \$0.10 each. (a) $\$ 0.10$ each. (a) $\$ 0.20$ each. a) \$0.10 each. (a) $\$ 0.20$ each. (a) $\$ 0.10$ each. (a) $\$ 0.40$ each.

These questions serve to "capture" the indifference curve between own payoffs and payoffs to the other player, in the spirit of Revealed Preference theory. As the price of giving to the other player dropped, one would expect to see choices that imply ${ }^{12}$ that no less was allocated to the other player. Thus, answers to decision \#10 and \#11 would be expected to show that the pass rate in \#11 is no less than the pass rate in \#10. In the extreme, with sufficiently high substitutability in the preferences of the player between own-payoff and payoff to the other player, one would see a $0 \%$ pass rate in $\# 10$ and a $100 \%$ pass rate in $\# 11$.

But they also imply different payoffs to the experimenter, depending on how the subjects view this task. The maximal payout by the experimenter was for decision \#10 or decision \#11, and would be $\$ 16.00$ if the subject passed $0 \%$ or $100 \%$ of the 40 points to the other player, respectively. So if the subject only cared about extracting money from the experimenter for either player, the

\footnotetext{
${ }^{12}$ Directly or indirectly.
} 


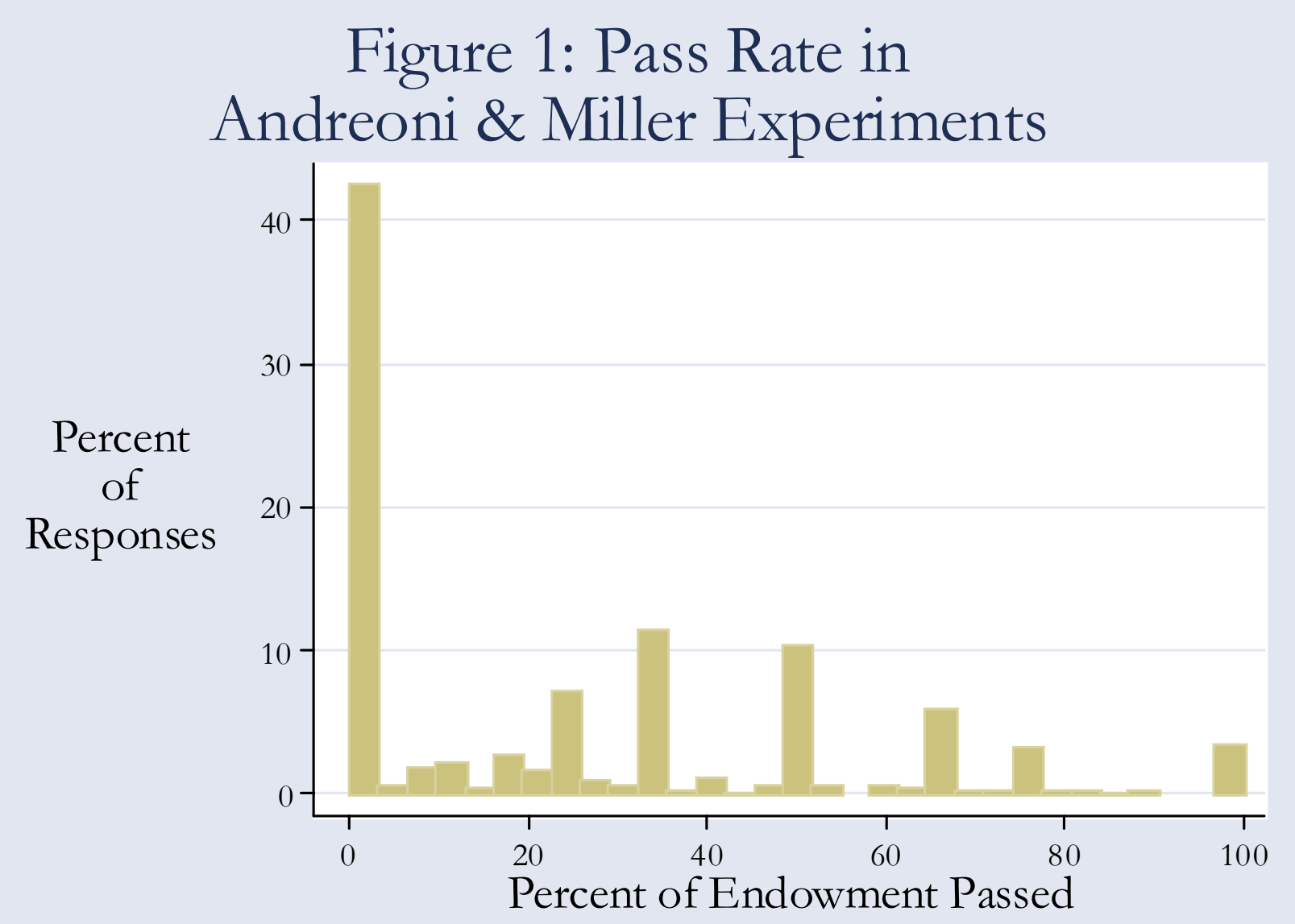

same responses would be observed as if the player had been altruistic (and had high enough elasticity of substitution between the payoffs of the two players). Thus one cannot say if the observed behavior in this example is due to altruism towards the other player or inefficiency aversion.

The smallest payout by the experimenter was for decision \#6, and would be $\$ 6.00$ irrespective of how the subject allocated the endowment of points. So in this instance any allocation to the other player is a sign of some altruism.

What does the data from the Andreoni and Miller [2002] experiments suggest? Figures 1 and 2 display the pass rate, calculated as the percentage of the initial endowment of points that the 


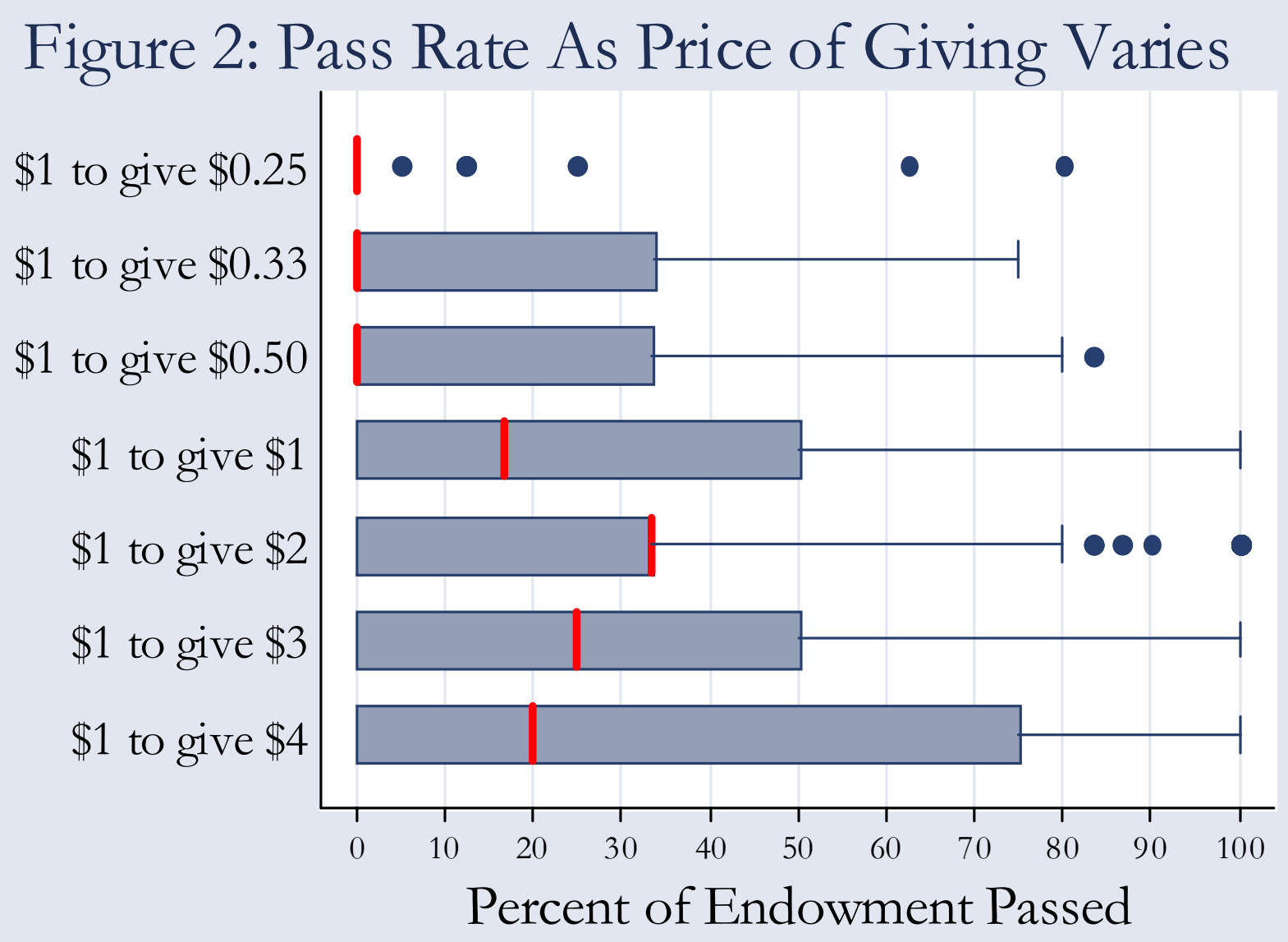

subject passed to the other player. ${ }^{13}$ Obviously many subjects were stingy! Only $58 \%$ of responses involved passing a positive amount to the other player. By itself this is not a problem for their design. If a given subject never gave to the other player, however, there is no interesting test of consistency with rationality - nor is there a violation, of course, since this subject could just care less about the well-being of the other player. It turns out that $23 \%$ of the responses were from subjects who gave nothing to the other player in all decisions. The responses of these players should not be discarded, but they should be identified since they are not particularly interesting for some purposes

13 Their experiment used an endowment of tokens, which were converted to points at the exchange rates shown in the instructions, and then these points were converted to currency at a fixed rate of 10 cents per point. We simplify things by instructing the subjects directly in points. 
(e.g., the tests of rationality underlying consistency with the axioms of Revealed Preference). ${ }^{14} \mathrm{We}$ focus in our design on the range of prices that generate significant contributions, to better identify the extent of altruism. ${ }^{15}$

\section{Giving to Charities}

Eckel and Grossman [2003] extended the Dictator Game considered above, and in their earlier work on altruism towards other individuals, to consider charitable contributions to organizations. They allowed subjects to pick one of ten designated charities that met tax eligibility standards for exemptions in Texas, where the experiments were conducted. Their design then matched the earlier Dictator Games: subjects had differing endowments across decisions, and differing rates at which their contributions would end up in the pocket of their designated charity.

Eckel and Grossman [2003] were particularly interested in the effects of "rebates" or "matching subsidies" on charitable contributions - in theory, the two should have the same effect if chosen appropriately, as they were in their design. A matching subsidy works by some external body providing a match to the charitable contributions of the donor, so that every dollar contributed generates more than one dollar to the charity. A rebate works by the charity itself, or some external body such as the government through tax exemptions, effectively returning monies to the donor in

\footnotetext{
${ }^{14}$ It would be appropriate to re-run the tests undertaken by Andreoni and Miller [2002] with these subjects removed. However, since they find so few violations of rationality with them included, there is not likely to be much change if one does.

${ }^{15}$ Multipliers that effectively tax transfers intended to redistribute might engender relatively little altruism, but they are of considerable practical relevance. In public finance, a multiplier less than one corresponds to there being a marginal efficiency cost of redistribution, due to the use of a distortionary taxation and/or subsidy scheme for implementing the transfers. Ballard [1988] employs a computable general equilibrium model of the United States to calculate that every dollar transferred from the richest income groups to the poorest groups costs the former between $\$ 1.50$ to $\$ 2.30$, so that the marginal efficiency cost of the $\$ 1$ transferred is between $\$ 0.50$ and $\$ 1.30$. Of course, these specific numbers are sensitive to the distortions assumed and used in the transfer policy, but the marginal efficiency cost is generally positive for all relevant policies considered by Ballard [1988]. Thus, further study of that domain is worthy, even if it unlikely to generate considerable levels of altruism in the stark, abstract setting of the laboratory.
} 
some proportion to the amounts donated..$^{16}$

Eckel and Grossman [2003] find that contribution rates, or pass rates as defined earlier, are roughly the same in the rebate or matching subsidy treatments. In both cases the pass rates are remarkably close to $50 \%$. This implies a much higher dollar contribution under the matching subsidy treatment, simply from the arithmetic of the two subsidy rules and the control for identical initial endowments. They conclude that matching subsidies might be an attractive way to replace rebates based on tax exemptions, which is desirable as part of some broad-based reform of the tax system to encourage uniformity.

One possible explanation for this framing effect is that subjects might perceive the matching subsidy as entailing a contribution from somebody else who might otherwise not make a contribution, and fail to perceive the rebate subsidy in the same manner. If the subject valued the contribution to the charity more than the income level of that third party, the subsidy offers a way for the subject to increase their own utility at the expense of the third party.

Davis, Millner and Reilly [2003] focus on the fact that the pass rates were remarkably similar under the two treatments, and hypothesize instead that this framing result might be due to a simple calculation error by the subjects. They modify the original design to make the effects of the two treatments blindingly transparent to subjects, and find that pass rates are indeed closer to predicted levels. Their results are consistent with some calculation error, but do not eliminate it.

One particularly striking methodological contribution of Davis, Millner and Reilly [2003] is a recognition of the potential importance of sample composition effects and a general way of dealing

\footnotetext{
16 Although tax exemptions are the important real-world metaphor for the rebate subsidy, and are sizeable, they amount to a virtual rebate in the sense that they are rarely actually rebated. An actual rebate would occur if someone made a sizeable donation to a tax-exempt organization but did not allow for that in their regular tax payments to the government, resulting in a physical rebate check being sent back to the taxpayer. Most taxpayers presumably allow for the effects of large donations by taking appropriate deductions throughout the year. This field counterpart of the experimental treatment may be of some importance when subjects are deciding how to respond to rebates in the lab.
} 
with them. They find a statistically significant sex effect, such that women are more altruistic in each of their treatments. ${ }^{17}$ However, since their three treatment samples contained $58 \%, 65 \%$ and $37 \%$ females, respectively, they would have observed a difference in average pass rates if they failed to condition on the sample composition differences. They did so, using a statistical model of predicted pass rates that includes controls for sex, and report the conditional pass rates assuming identical sample compositions in each treatment. ${ }^{18}$ We generalize their approach.

\section{Experimental Design}

In all treatments we had one subject that was the Dictator. In treatments $\mathrm{O}$ and $\mathrm{C}(\mathrm{O})$ we also had one subject that was a Peasant. Each had separate tasks, although we focus here on the Dictators.

The basic design we use builds on Andreoni and Miller [2002], as discussed and illustrated above. Each subject makes 10 decisions, each of which entails an allocation of points to himself and an allocation to pass. In treatment $\mathrm{O}$ the points passed are assigned to another player in the room, following Andreoni and Miller [2002]. In treatment C the points passed are assigned to a specific charity, in the spirit of Eckel and Grossman [2003]. In each case we say "nothing" about what happens to the residual, although it is clear that the experimenter is effectively paying more to the subjects when a point is allocated to an account that has a larger multiplier.

${ }^{17}$ This a priori likelihood was well known given the earlier work of Brown-Kruse and Hummels [1993], Bolton and Katok [1995], Eckel and Grossman [1998] and Andreoni and Vesterlund [2001] with closely related games. Ortmann and Tichey [1999; p.328] went further and recognized the need for experimenters to "... take gender effects into account when they choose their subjects and/or control for these effects when they evaluate their results."

${ }^{18}$ Following the procedures of Harrison and Lesley [1996], one could also use the same methods to predict population responses by substituting population averages for observable characteristics. This requires the maintained assumption that the marginal effect of the observed characteristic is reliably estimated from the lab, sample responses. This may be a strong and untenable assumption, given the self-selection and narrow range of characteristics inherent in the population that is sampled in the customary lab experiment. 
In treatment $\mathrm{O}(\mathrm{C})$ we follow treatment $\mathrm{O}$, but add some text to say that the experimenter has allocated up to a certain amount for each player pair, and that anything left over after the session will be sent to a specific but un-named charity. ${ }^{19}$ Similarly, in treatment $\mathrm{C}(\mathrm{O})$ we follow treatment $\mathrm{C}$, but add some text to say that the experimenter has allocated up to a certain amount for each player pair, and that anything left over after the session will be assigned to another player selected at random and without replacement. ${ }^{20}$

In all treatments the following text was used:

We will select one of your decisions to actually implement at the end of the session. We have allowed for up to $\$ 32$ to be paid out for the decision that is selected, multiplied by the number of pairs of subjects here today. This is the maximum amount that can be paid out, depending on your choices and the roll of the die selecting the decision to be implemented. Depending on your choices, and the decision picked to be implemented, we might not need to pay out as much as $\$ 32$ per pair.

This text effectively informed the subject that we had the cash to make the payments necessary under the rules of the task. We decided to be explicit in this matter in our control treatments since we had to be explicit about it our research treatments, and we wanted the sole difference between the treatments to be the consequences of leaving money on the (experimenter's) table. If we had not been so explicit, there would have been two differences between our control and research treatments: the reminder that we planned conservatively in terms of the "cash box," and a statement about the disposition of residuals. The comparable text in treatment $\mathrm{O}(\mathrm{C})$ included the above text plus

\footnotetext{
${ }^{19}$ Eckel and Grossman [1996b; fn.9, p.185] note that one adds a confound by comparing altruism towards an unknown individual with altruism towards a known charity. They conjecture that their results, showing greater contributions to the charity than the individual, and not due to this confound. Our results confirm their conjecture. Small and Loewenstein [2003] examine this issue by carefully designing an experiment in which the recipient can be identified as a specific individual or family, but no information about the recipient was provided. They find an effect on apparent altruism.

${ }^{20}$ These treatments reverse the approach employed by Frank [1998] in the context of ultimatum game experiments, where he told subjects that he would burn any residual! In his experiments he used regular stamps as the experimental numéraire. It is arguable that the novelty of seeing cash or cash-like stamps actually put to fire might have been a confound. In some nations it is illegal to deliberately destroy legal tender.
} 
this extra explanation at the end of the paragraph:

Any monies left will be paid to a public charity. The name and address of the charity is in a sealed envelope which we will open at the end of the session. We will write a check to the charity at the end of the session, seal it in an envelope, and you can come with us to the nearest public mailbox to see it mailed.

In treatment $\mathrm{C}(\mathrm{O})$ we added this extra text instead:

Any monies left will be paid to one other subject in the room, selected at random.

So the only difference between the experiments in this respect was the addition of the extra text for the $\mathrm{O}(\mathrm{C})$ and $\mathrm{C}(\mathrm{O})$ treatments.

We deliberately chose residual claimants for these tests that would be transparently understood, plausible in the context of our experiment, and generate differences in preferences across our sample. One could easily imagine variants that would not elicit large differences in preferences. In the $\mathrm{O}(\mathrm{C})$ treatment, for example, what if we confronted students in Colorado with residuals that would be contributed to United Way of Florida in one situation and then to United Way of Georgia in another situation. There might still be a large difference between preferences for the residual in $\mathrm{O}$ as compared to these two together, but a priori one could expect that differences between the two United Way treatments would be minimal. Since our objective is simply to identify if the specification of the residual claimant mattered at all, these clear extremes were appropriate. But any field application would have to evaluate what alternatives were appropriate for that context. We also expect that the sensitivity of results will depend on the sample, and indeed stress below the need to condition inferences on comparable samples. In general, we expect these specification and sampling issues to become more important in field settings than in lab settings, due to the greater heterogeneity of contexts and samples that one is likely to encounter in the field.

Each subject was asked to make 10 choices. These were patterned after Andreoni and Miller [2002], but only included returns to giving of 1 or more: 
1. Divide 75 points: Hold___ @ $\$ 0.20$ each, and Pass

2._Divide 40 points: Hold__@ @ \$0.20 each, and Pass

3. Divide 75 points: Hold___ @ \$0.20 each, and Pass

4. Divide 60 points: Hold___ @ \$0.20 each, and Pass

5. Divide 40 points: Hold__@ @ $\$ 0.50$ each, and Pass

6. Divide 100 points: Hold__@ @ $\$ 0.10$ each, and Pass

7. Divide 60 points: Hold___ @ \$0.20 each, and Pass

8. Divide 80 points: Hold___ @ $\$ 0.20$ each, and Pass

9. Divide 40 points: Hold___ @ $\$ 0.20$ each, and Pass

10. Divide 40 points: Hold___ @ $\$ 0.20$ each, and Pass

(a) $\$ 0.40$ each. (a) $\$ 0.60$ each. @ $\$ 0.20$ each. (a) $\$ 0.40$ each. (a) $\$ 0.50$ each. @ $\$ 0.20$ each. a) $\$ 0.30$ each. @ $\$ 0.40$ each. @ \$0.80 each.

Three versions of these questions were employed in each session, varying the order of each question.

\section{Experiments}

The experiments were conducted over two consecutive days in late January, 2004 at the University of Denver. This is a small, private college, with an undergraduate enrollment of only 4,500 in 2003. Residents of Colorado make up roughly $45 \%$ of the incoming class, and undergraduate tuition costs around $\$ 25,000$ per year. Subjects were recruited in classes with large sections, and all subjects were undergraduates.

We had 173 subjects across all treatments. In treatments $\mathrm{C}, \mathrm{O}, \mathrm{C}(\mathrm{O})$ and $\mathrm{O}(\mathrm{C})$ we had 28, 58, 31 and 56 subjects, respectively, so that we would have roughly 30 proposers in each treatment. Subjects were randomly assigned to treatment, and did not know anything about the purpose of the experiment when recruited to specific sessions. Each of the $\mathrm{C}$ and $\mathrm{O}$ sessions were conducted in one large classroom, and sessions $\mathrm{C}(\mathrm{O})$ and $\mathrm{O}(\mathrm{C})$ in two large, adjacent classrooms. All subjects met in one classroom initially in sessions $\mathrm{C}(\mathrm{O})$ and $\mathrm{O}(\mathrm{C})$, and were then taken to the other room if they randomly received an "odd numbered" subject ID number. These simple logistics served to make it clear to all subjects that there were "real people" in the other room, since this was referred to in the instructions. 
The instructions were relatively brief, and we read them out as the subjects had an opportunity to read along. This serves to slow down those subjects that want to just skip through the instructions and make their decisions, so that all subjects have an equal opportunity to "internalize" the instructions. Johnson was the experimenter for Dictators in all sessions, and Harrison was the experimenter for Peasants in the $\mathrm{O}$ and $\mathrm{O}(\mathrm{C})$ sessions.

Our sample demographics matched the general undergraduate mix at the University of Denver. Over $61 \%$ of the sample were female. Only $2.3 \%$ were black, and $8.1 \%$ were Hispanic. Freshmen and Sophomores made up $33 \%$ and $46 \%$ of the sample, respectively. Although age ranged from 18 up to $24,84 \%$ of the sample were aged 18,19 or 20 , so there is relatively little variation in this characteristic. The complete list of individual demographic questions is provided in an Appendix.

To avoid any confounds from specific knowledge, we did not identify the charity that we were using. We did provide an opportunity to all subjects to examine the check being written to the charity, and to come with us to mail it immediately after the session concluded. In fact, the charity was the American Civil Liberties Union of South Carolina Foundation, a 501(c)3 non-profit organization, and payments totaling $\$ 1,143$ were made to them as the result of these experiments.

Each subject received $\$ 10$ for showing up and participating in the experiment. This was slightly on the generous side compared to most laboratory experiments with a convenience sample of students, but we were unsure about the response of students at the University of Denver to standard recruitment procedures. Moreover, the base student population was relatively small, adding to our concern about enrollment. Finally, there had been no fresh snow on the local ski resorts for some weeks, heightening our concern that Mother Nature would increase the opportunity cost of 
attending the experiment at the last minute. ${ }^{21}$

Average payments, in addition to the show-up fee, were $\$ 20.67$. However, this includes one "happy, happy" subject in the $\mathrm{C}(\mathrm{O})$ treatment that received a payout of $\$ 441$. Removing him, the average was $\$ 18.25$. Individual payments ranged from a low of $\$ 0.20$ to a high of $\$ 32$.

\section{Results}

\section{A. Apparent Altruism}

Figure 3 displays the unconditional pass rates observed in our experiments. ${ }^{22}$ The pass rate is defined as the percent of the endowment which is passed, so that we normalize across the different endowments in each decision. The horizontal axis shows the price of giving, which is just the ratio of the money received by the other party to the money sent. Thus if $\$ 1$ was passed and became $\$ 3$ when received by the other party, the price of giving is 3 . The top two lines, in red, show the pass rates for treatments $\mathrm{C}$ and $\mathrm{C}(\mathrm{O})$; the bottom two lines, in black, show the pass rates for treatments $\mathrm{O}$ and $\mathrm{O}(\mathrm{C})$. The lines in Figure 3 are based on fractional polynomial fits of the observed choices, but essentially reflect the unconditional averages at each price; more formal statistical tests are reported below.

Figure 3 displays unconditional behavior in the sense that we do not condition on the fact that our samples differed across the four sessions. For example, women made up $71 \%$ of the

\footnotetext{
${ }^{21}$ Fortunately for us, there was no snow until the day after the experiment.

22 Detailed results for pass rates and earnings are displayed in an appendix (available on request).
} 


\section{Figure 3: Apparent Altruism}

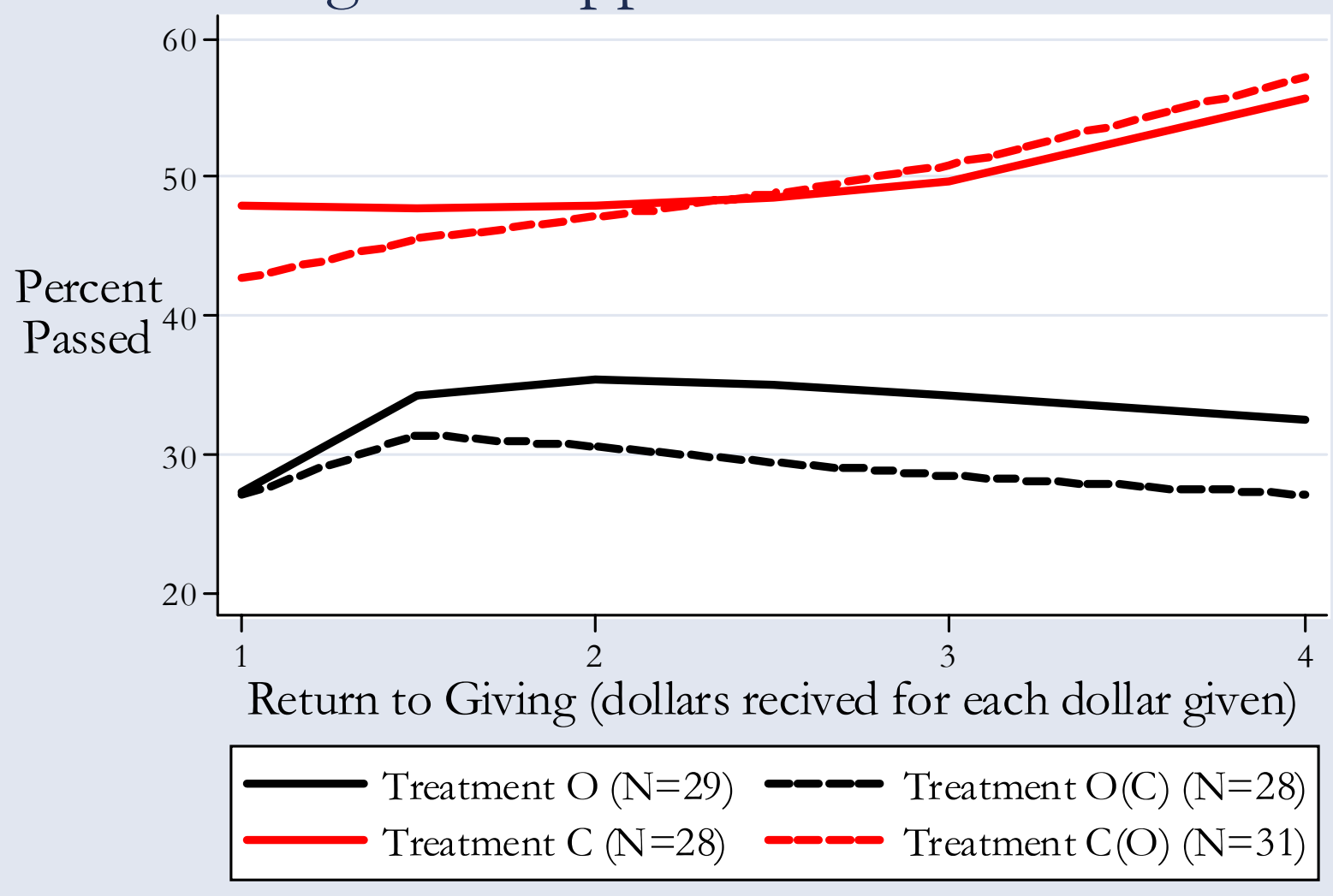

samples for the $\mathrm{C}$ and $\mathrm{O}(\mathrm{C})$ treatments, but only $55 \%$ of the sample for the $\mathrm{O}$ treatment and $51 \%$ of the sample for the $\mathrm{C}(\mathrm{O})$ treatment. If altruistic preferences differ for men and women, as one would expect from the previous literature, then this difference in sample composition could distort inferences from raw data such as in Figure 3. With sufficient sample sizes and random assignment to treatment, this would not be an issue. But when there are many possible characteristics that can affect response, other than sex, the sample sizes needed for randomization to be effective are enormous. $^{23}$

${ }^{23}$ For example, Davis, Millner and Reilly [2003] collected information on the sex, age, race, marital status, family structure, education level, and major of their subjects, but only corrected for sample composition effects of sex. A panel tobit model replicating their results (their Table 7) are easily extended to show significant effects on pass rates of age, race, education level and major. Whether or not there are large sample composition effects in terms of these variables, the logic of their correction for sample composition effects extends obviously. 


\section{B. Revealed Altruism}

Figure 4 reports conditional behavior assuming that responses can be characterized by a statistical model of behavior that controls for differences in individual sample characteristics. Table 1 reports the statistical specification underlying these displays, so that one can test for significance of effects. We focus on a standard array of "objective" observable characteristics, as well as a random effects specification to control for any unobserved individual heterogeneity beyond those characteristics. ${ }^{24}$ Specifically, we include sex, age, race, ${ }^{25}$ personal and household income,${ }^{26}$ and a measure of multiple-person households. ${ }^{27} \mathrm{We}$ also include controls for the return to giving, ${ }^{28}$ the initial endowment of points, and interactions between the return to giving and sex. ${ }^{29}$ The estimation procedure is a two-limit Tobit model, recognizing that pass rates cannot be below 0 or above 100 . To generate Figure 4, each model is estimated on the sample in just one treatment, and then predicted pass rates ${ }^{30}$ are calculated using those estimated coefficients and the common sample characteristics across all four treatments. Thus we ensure that the sample composition is controlled for when generating predicted pass rates.

Four general features of Figure 4 are important.

${ }^{24}$ Our data constitutes a panel, with 10 observations for each individual.

25 Classified as "white" and "non-white" only, given the paucity of breakdowns in the latter group.

${ }^{26}$ One dummy variable picks out if the own-income or parental income is greater than $\$ 65,000$ but less than $\$ 100,000$, and another dummy variable picks out if either is greater than $\$ 100,000$.

27 A dummy variable picking out if the subject lives with one or more people in the same household.

28 Taking on values $1,1 \frac{1}{2}, 2,2 \frac{1}{2}, 3,3 \frac{1}{2}$ and 4 . This variable is also controlled for in quadratic and cubic forms.

29 The last interaction is implied by the findings of Eckel and Grossman [1996a] and Andreoni and Vesterlund [2001].

30 There are several ways in which one can generate predicted values using the Tobit model, depending on how one recognizes the effects of censoring at the limits. We assume that the predicted value takes on the limit value if it would otherwise be below or above. Thus we implicitly use the estimated model to construct the linear production and then truncate at the limit points if appropriate, where the linear prediction assumes that the random effect for each individual is zero. This procedure is consistent with the latent process that is assumed to be generating the data employed in the Tobit model. An alternative procedure is to predict the expected value conditional on the pass rate being censored. Finally, one can predict the pass rate and ignore the effects of the limit points. These alternatives lead to more or less damped effects than our preferred prediction procedure, as one might expect a priori. 


\section{Figure 4: Apparent and Revealed Altruism}
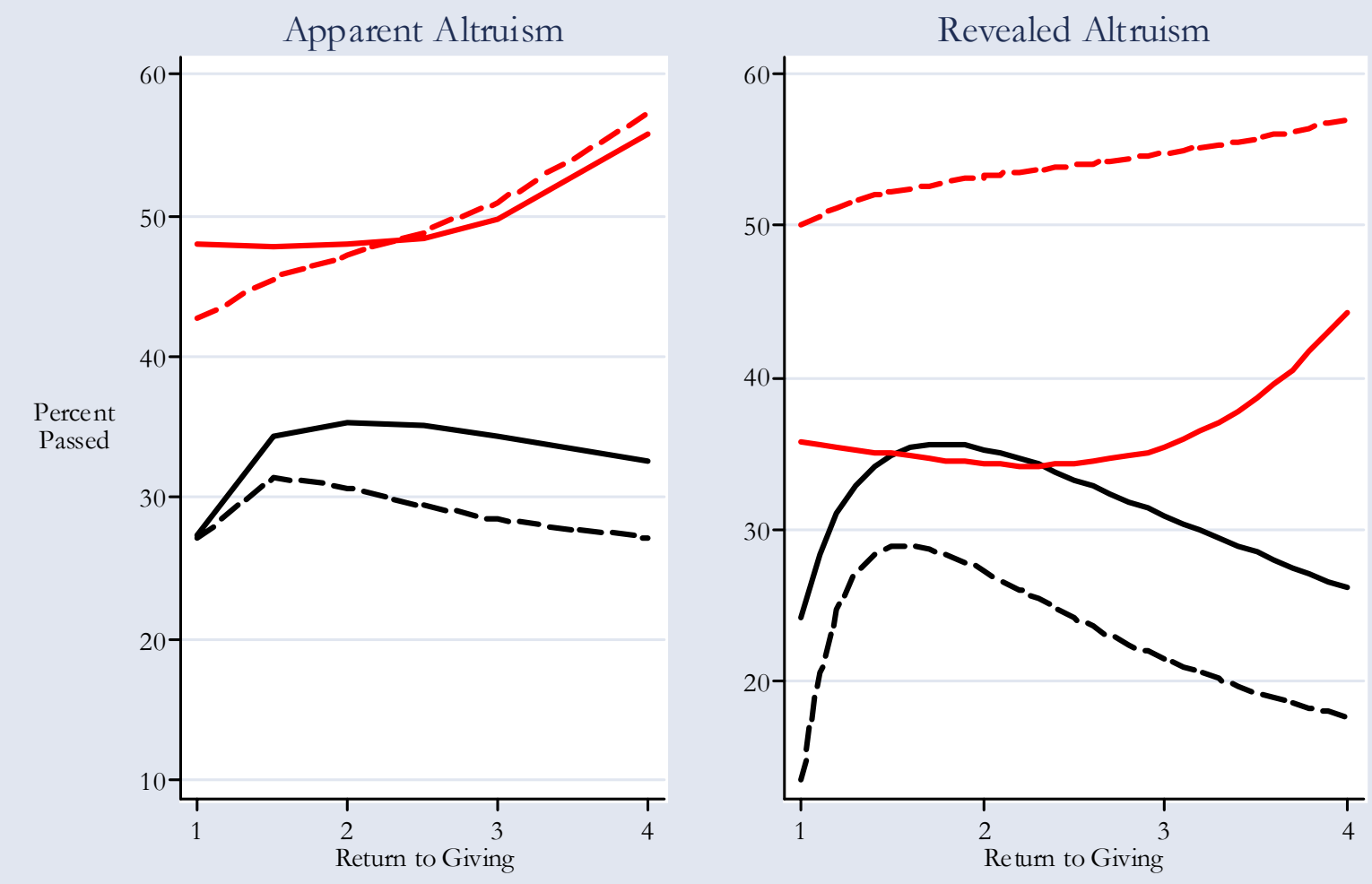

First, the use of common, synthetic samples generates differences in the responses when one compares the same treatment in the left panel and the right panel. For example, pass rates for treatment $\mathrm{C}$ (the solid red line) are much lower when one accounts for the fact that it had a different sample than other treatments. Similarly, pass rates for treatments $\mathrm{O}$ and $\mathrm{O}(\mathrm{C})$ are generally lower than in their unconditional counterparts. The general methodological point is that one simply cannot detect such differences if questions about individual characteristics are not asked. ${ }^{31}$ Many experiments do not include a questionnaire on individual characteristics, or limit attention to just one or two characteristics. For some purposes, where there is little a priori belief that responses will vary with observable

31 It is conceivable that one could still undertake some fixed-effect estimation and then apply "recombinant estimation" methods in the spirit of Mitzkewitz and Nagel [1993], Mehta, Starmer and Sugden [1994] and Mullin and Reiley [2004]. Or one could use those methods in addition to the methods we use to control for observables. 
characteristics, this is a reasonable economy in terms of experimental procedure. On the other hand, questionnaires do not take a long time to complete, and often serve to allow subjects time to settle into the experiment before the main tasks begin.

Second, altruism towards an unspecified generic charity tends to be greater than altruism towards another subject, and this general preference holds at all levels of the return to giving when one controls for the efficiency confound. This result is consistent with evidence reviewed earlier, particularly Eckel and Grossman [1996b], but is the first time that it has been demonstrated for subjects drawn from the same population at the same time, in essentially the same experimental task, and with the same level of knowledge about the specific recipient. Hence there are no other confounds that might affect this conclusion. ${ }^{32}$ The implication is that there is no single "propensity to be altruistic," but that it depends on the context of the type of recipient. This is also not surprising, but worth documenting carefully so that claims of altruism in one setting are not automatically assumed to apply in different settings. Experimenters that need to identify the altruism in their subject pool and context will simply have to build in a test for it. ${ }^{33}$

The general pattern of preferences reflected in the revealed altruism results are consistent across treatments. Comparing treatments $\mathrm{C}$ and $\mathrm{O}$, when the residual claims are the same and

\footnotetext{
32 One possible confound, controlled for by Eckel and Grossman [1996b] following Hoffman, McCabe, Shachat and Smith [1994], is the experimenter's knowledge of specific contributions by each subject. They implemented a double-blind procedure which ensures that this will not be possible, and which should have been understood as such by the subjects. We are interested in developing experimental procedures for detecting altruism that can be used as components of larger, field experiments trying to identify "trust," and it is desirable that one not add the extra layer of complexity needed for a double-blind design. Moreover, we need to collect information on the individual characteristics of subjects, and we do not know of an attractive double-blind design that allows one to do that and claim that one cannot use the characteristics to identify (perhaps probabilistically) an individual subject. The only procedures that would permit such an investigation would require "randomized responses" to the questions identifying characteristics, or "randomized questions" with the same response domain, and that would dramatically expand the sample size needed (e.g., Goodstadt and Gruson [1975]). Of course, one is able to collect information on individual characteristics in extreme cases in which all individuals have one or other characteristic, as in the same-sex double-blind experiments of Eckel and Grossman [1996b]. They recognize (fn.9) that one cannot generally identify individual characteristics and associate them with specific individual responses in double-blind experiments.

33 The test should also be in-sample, unless unusually large samples are used.
} 
rebound to the experimenter, we observe that subjects tend to prefer giving to a charity than to some other subject. This effect is particularly clear for higher returns to giving, although it also holds for the lowest return to giving. Hence when we substitute the charity for the experimenter in treatment $\mathrm{O}(\mathrm{C})$ we observe a reduction in contributions to the other subject by comparison to treatment $\mathrm{O} .{ }^{34}$ Conversely, when we substitute some other subject for the experimenter in treatment $\mathrm{C}(\mathrm{O})$, we observe an increase in contributions to the charity by comparison to treatment $\mathrm{C} .{ }^{35}$ The implication is that subjects, on average, rank contributions to a charity over contributions to the experimenter, and then rank contributions to the experimenter over contributions to another subject. Although this particular pattern is not required for our hypothesis about the residual claim to be valid, it happens to be qualitatively consistent internally as well as with related experimental data.

Third, we observe weak evidence in three cases for a "relative price" effect on giving, but strong evidence in one case. The two treatments with the efficiency confound, $\mathrm{C}$ and $\mathrm{O}$, exhibit evidence for increased giving when the return is higher. But this evidence only appears for high levels of the return in the case of treatment $C$, and for low levels of the return in the case of treatment O. On the other hand, these two treatments have a confound, so it is really treatments $\mathrm{C}(\mathrm{O})$ and $\mathrm{O}(\mathrm{C})$ that are of concern in terms of the substitution effect. In treatment $\mathrm{C}(\mathrm{O})$ we observe a striking effect in which increases in the return to giving to a charity generate increases in amounts allocated, and in treatment $\mathrm{O}(\mathrm{C})$ we observe weak evidence at low levels of the return to giving. ${ }^{36}$

Finally, we obtain strikingly disparate predictions of the effect of the efficiency treatment depending on the context. In the case of altruism towards charity, the efficiency treatment implies

\footnotetext{
34 These are the two bottom lines on the right panel of Figure 4.

35 These are the two top lines on the right panel of Figure 4.

36 The apparent decline in pass rates for higher returns to giving in $\mathrm{C}(\mathrm{O})$ is not statistically significant.
} 
that the apparent extent of altruism actually under-stated the true extent of altruism. On the other hand, in the case of altruism towards another person, the efficiency treatment implies that "apparent altruism" overstates true, "revealed altruism." The result for charity is due largely to the sample composition effects on the control experiment $\mathrm{C}$. The result for altruism is consistent with the qualitative pattern observed in the raw, unconditional data, although the levels of altruism in treatments $\mathrm{O}$ and $\mathrm{O}(\mathrm{C})$ are lower. Of course, these claims about overstating or understating the quantitative extent of altruism apply only to the comparisons employed here. Our general point is that the measured extent of altruism will likely be sensitive to the way in which the residual claimant is defined, and that this will likely interact with subject pool differences.

\section{Conclusions}

Behavior in most of the games studied by economists is complex. Ultimatum games offer a cocktail of potential confounds when analyzed rigorously, including risk attitudes, altruism, reciprocity norms, expectations, intentions, the ability to backward induct, and finally rationality (in the residual sense of the ability to put all the pieces together).$^{37}$ Public good contribution games ${ }^{38}$ and Trust games ${ }^{39}$ offer a similar witches' brew, making it hard to convincingly identify what is driving behavior. And yet these game forms are the behavioral staple of increasingly elaborate and tightly specified models of other-regarding preferences that require striking leaps of faith in joint hypothesis tests.

We focus on one of the least confounded game forms, the Dictator Game with varying multipliers, because it offers the humble prospect of allowing the experimenter to identify the extent

\footnotetext{
${ }^{37}$ Harrison and McCabe [1996].

38 Palfrey and Prisbey [1997].

${ }^{39}$ Cox [2004].
} 
of altruism in an individual. We encounter two generic methodological confounds. The first is the role that the "third man" plays in the experiment: different assumptions about the residual claims provided by the experimenter matter. ${ }^{40}$ Subjects are playing a general equilibrium game which we have been analyzing as a partial equilibrium game, and inferential loose ends are the result. The second is the surprising role that mundane sample composition effects can have. Each confound has a constructive solution, and applies more generally than the identification of altruism in Dictator

\section{Games.}

We conclude that altruism can indeed be identified using laboratory experiments, that it exists $^{41}$, and that it varies considerably across a given subject pool in an identifiable manner. ${ }^{42}$ Addressing the potential methodological confounds in previous work changes the extent to which altruism can be identified - in some cases it is smaller than prevailing procedures would suggest, but in some cases it is actually larger.

40 This expression is due to Martin Dufwenberg, and borrows from Tucker [1950]. In that remarkable one-page memo introducing the non zero-sum two-player Prisoners' Dilemma, he notes simply that the "game becomes zero-sum by introducing the State as a third player."

${ }^{41}$ Some commentators view the existence of altruistic preferences as "proving" that traditional economic theory is false in some fundamental way. What it shows is that certain specific assumptions, such as individual preferences being defined solely over own payoffs, are false in some settings and for some people. However popular and inappropriate those assumptions have been, they are not fundamental. For example, in 1976 Jack Hirshliefer's Price Theory and Applications (p.72ff.), a popular undergraduate textbook, contained a simple exposition of altruistic preferences.

${ }^{42}$ Two popular, parameterized models of fairness are quite explicit about allowing for individual heterogeneity in preferences: see Fehr and Schmidt [1999; p.818] and Bolton and Ockenfels [2000; Assumption 4, p.172]. They fare poorly when required to explain simple experimental data similar to ours and forced to abandon the assumption of heterogeneity: see Charness and Rabin [2002] and Engelmann and Strobel [2004], for example. Charness and Rabin [2002; p.821, fn. 6] honestly acknowledge that they ignore this aspect of the "difference aversion" models, and that "We have not tested for individual differences and correlation across games, and neither our analysis nor our model deals with heterogeneity of subject preferences.” (p. 849). When formally evaluating their data, Charness and Rabin [2002; p.838] opt for an all-too-common device in experimental economics, allowing individual heterogeneity to be bundled into the error term: their analysis "... assumes that all subjects share a fixed set of preferences, and that observed behavior corresponds to individuals implementing these preferences with error." The dangers of this approach in tests of expected utility theory are by now well known, and are discussed in Ballinger and Wilcox [1997]. 
Table 1: Estimation Results from Panel Tobit Model of the Pass Rate

\begin{tabular}{|c|c|c|c|c|c|c|}
\hline Variable & Coefficient & Std. Err. & $\mathrm{z}$ & $\mathrm{P}>|\mathrm{z}|$ & \multicolumn{2}{|c|}{ [95\% Confidence Interval] } \\
\hline \multicolumn{7}{|c|}{ Primary Treatments } \\
\hline Efficiency & -28.91 & 3.56 & -8.12 & 0.000 & -35.89 & -21.92 \\
\hline Charity & 26.40 & 3.28 & 8.05 & 0.000 & 19.97 & 32.83 \\
\hline Charity $\times$ Efficiency & 17.36 & 3.69 & 4.7 & 0.000 & 10.12 & 24.60 \\
\hline \multicolumn{7}{|c|}{ Design Controls } \\
\hline Return & 51.74 & 19.30 & 2.68 & 0.007 & 13.92 & 89.57 \\
\hline Return $^{2}$ & -20.30 & 8.76 & -2.32 & 0.020 & -37.47 & -3.14 \\
\hline Return $^{3}$ & 2.66 & 1.18 & 2.25 & 0.024 & 0.34 & 4.98 \\
\hline Endowment & 0.07 & 0.06 & 1.12 & 0.262 & -0.05 & 0.19 \\
\hline \multicolumn{7}{|c|}{ Individual Subject Controls for Sex } \\
\hline Endowment $\times$ Female & -0.15 & 0.07 & -2.2 & 0.028 & -0.28 & -0.02 \\
\hline Return $\times$ Female & -4.08 & 1.59 & -2.57 & 0.010 & -7.20 & -0.97 \\
\hline Efficiency $\times$ Female & 23.65 & 3.95 & 5.99 & 0.000 & 15.92 & 31.38 \\
\hline Charity $\times$ Female & -17.99 & 3.39 & -5.31 & 0.000 & -24.63 & -11.35 \\
\hline Female & 13.71 & 6.89 & 1.99 & 0.046 & 0.21 & 27.21 \\
\hline \multicolumn{7}{|c|}{ Additional Individual Subject Controls } \\
\hline Non-White & -20.59 & 2.40 & -8.57 & 0.000 & -25.30 & -15.88 \\
\hline Age & 0.08 & 0.72 & 0.12 & 0.906 & -1.32 & 1.49 \\
\hline Work & 11.01 & 1.84 & 6 & 0.000 & 7.41 & 14.61 \\
\hline Income1 & -20.57 & 2.41 & -8.53 & 0.000 & -25.29 & -15.84 \\
\hline Income2 & -6.77 & 2.00 & -3.37 & 0.001 & -10.69 & -2.84 \\
\hline Hhd & 5.02 & 2.35 & 2.14 & 0.032 & 0.42 & 9.62 \\
\hline Constant & -15.23 & 18.63 & -0.82 & 0.414 & -51.74 & 21.28 \\
\hline \multicolumn{7}{|c|}{ Estimates of Error Terms } \\
\hline$\sigma_{\mathrm{u}}$ & 26.80 & 0.91 & 29.43 & 0.000 & 25.01 & 28.58 \\
\hline$\sigma_{\mathrm{e}}$ & 19.36 & 0.47 & 40.9 & 0.000 & 18.43 & 20.29 \\
\hline$\rho$ & 0.66 & 0.02 & & & 0.62 & 0.69 \\
\hline
\end{tabular}

Legend: Unless otherwise noted, all variables are binary dummy variables. Charity denotes the $\mathrm{C}$ or $\mathrm{C}(\mathrm{O})$ treatments; Efficiency denotes the $\mathrm{O}(\mathrm{C})$ and $\mathrm{C}(\mathrm{O})$ treatments; Return is the multiplier on contributions, or the monetary "return" to giving; Endowment is the token endowment for a specific choice; Female denotes females; Non-White denotes self-reported ethnicity; Age is measured in years; Income1 (Income2) denotes parent or own income in 2003 over $\$ 65,000$ and less than $\$ 100,000$ (over $\$ 100,000$ ); Hhd indicates if the subject lives in a household with someone else; $\sigma_{\mathrm{u}}$ is the error term for the unobserved individual effect; $\sigma_{\mathrm{e}}$ is the general error term; and $\rho$ is the proportion of the total error term $\sigma_{u}+\sigma_{\mathrm{e}}$ that is due to $\sigma_{u}$. P-values reported as 0.000 are actually values that are less than 0.0005 . 


\section{References}

Andreoni, James, "Impure Altruism and Donations to Public Goods: A Theory of Warm-Glow Giving," Economic Journal, 100, June 1990, 464-477.

Andreoni, James, "Warm-Glow Versus Cold-Prickle: The Effects of Positive and Negative Framing on Cooperation in Experiments," Quarterly Journal of Economics, CX, February 1995, 1-21.

Andreoni, James, and Miller, John, "Giving According to GARP: An Experimental Test of the Consistency of Preferences for Altruism," Econometrica, 70(2), March 2002, 737-753.

Andreoni, James, and Vesterlund, Lise, "Which Is the Fair Sex? Gender Differences in Altruism," Quarterly Journal of Economics, February 2001, 293-312.

Ballard, Charles L., "The Marginal Efficiency Cost of Redistribution," American Economic Review, 78(5), December 1988, 1019-1033.

Ballinger, T. Parker, and Wilcox, Nathaniel T., "Decisions, Error and Heterogeneity," Economic Journal, 107, July 1997, 1090-1105.

Bolton, Gary E., and Katok, E., "An Experimental Test for Gender Differences in Beneficent Behavior,” Economics Letters, 48, 1995, 287-292.

Bolton, Gary E., and Ockenfels, Axel, "ERC: A Theory of Equity, Reciprocity, and Competition," American Economic Review, 90(1), March 2000, 166-193.

Brown-Kruse, Jamie, and Hummels, David, "Gender Effects in Laboratory Public Goods Contribution: Do Individuals Put Their Money Where Their Mouth Is?” Journal of Economic Behavior \& Organization, 22, 1993, 255-267.

Charness, Gary and Rabin, Matthew, "Understanding Social Preferences with Simple Tests," Quarterly Journal of Economics, 117(3), August 2002, 817-869.

Cherry, Todd L.; Frykblom, Peter, and Shogren, Jason F., "Hardnose the Dictator," American Economic Review, 92(4), September 2002, 1218-1221.

Cox, James C., "How To Identify Trust and Reciprocity," Games and Economic Behavior, 46(2), February 2004, 260-281.

Davis, Douglas D.; Millner, Edward L., and Reilly, Robert J., "Subsidy Schemes and Charitable Contributions: A Closer Look," Working Paper, Department of Economics, Virginia Commonwealth University, May 2003.

Eckel, Catherine C., and Grossman, Philip J., "The Relative Price of Fairness: Gender Differences in a Punishment Game," Journal of Economic Behavior \& Organization, 30, 1996a, 143-158. 
Eckel, Catherine C., and Grossman, Philip J., "Altruism in Anonymous Dictator Games," Games and Economic Behavior, 16, 1996b, 181-191.

Eckel, Catherine C., and Grossman, Philip J., “Are Women Less Selfish Than Men?: Evidence from Dictator Experiments,” Economic Journal, 108, May 1998, 726-735.

Eckel, Catherine C., and Grossman, Philip J., "Rebate versus Matching: Does How We Subsidize Charitable Contributions Matter?” Journal of Public Economics, 87, 2003, 681-701.

Engelmann, Dirk, and Strobel, Martin, "Inequality Aversion, Efficiency, and Maximin Preferences in Simple Distribution Experiments," Unpublished Manuscript, Charles University, Prague, February 2004; forthcoming, American Economic Review.

Fehr, Ernst, and Schmidt, Klaus, "A Theory of Fairness, Competition, and Cooperation," Quarterly Journal of Economics, 114, 1999, 817-868.

Forsythe, Robert; Horowitz, Joel L.; Savin, N.E., and Sefton, Martin, "Fairness in Simple Bargaining Games," Games and Economic Behavior, 6(3), 1994, 347-369.

Frank, Björn, "Good News for Experimenters: Subjects Do Not Care About Your Welfare,” Economic Letters, 61, 1998, 171-174.

Goodstadt, Michael S., and Gruson, Valerie, "The Randomized Response Technique: A Test on Drug Use," Journal of the American Statistical Association, 70(352), December 1975, 814-818.

Harrison, Glenn W., and Lesley, James C., "Must Contingent Valuation Surveys Cost So Much?” Journal of Environmental Economics \& Management, 31, June 1996, 79-95.

Harrison, Glenn W., and McCabe, Kevin A., "Expectations and Fairness in a Simple Bargaining Experiment," International Journal of Game Theory, 25(3), 1996, 303-327.

Harrison, Glenn W., and Rutström, E. Elisabet, "Doing It Both Ways -- Experimental Practice and Heuristic Context," Behavioral and Brain Sciences, 24(3), June 2001, 413-414.

Hirshleifer, Jack, Price Theory and Applications (Englewood Cliffs, NJ: Prentice-Hall, First Edition, 1976).

Hoffman, Elizabeth; McCabe, Kevin; Shachat, Keith, and Smith, Vernon L., "Preferences, Property Rights, and Anonymity in Bargaining Games," Games and Economic Behavior, 7(3), November 1994, 346-380.

Kritikos, Alexander and Bolle, Friedel, "Distributional Concerns: Equity- or Efficiency-Oriented?" Economics Letters, 73(3), December 2001, 333-338.

Ledyard, John, "Public Goods: A Survey of Experimental Research," in J. Kagel and A.E. Roth (eds.), Handbook of Experimental Economics (Princeton: Princeton University Press, 1995). 
Levine, David K., "Modeling Altruism and Spitefulness in Experiments," Review of Economic Dynamics, 1, 1998, 593-622.

Mehta, Judith; Starmer, Chris, and Sugden, Robert, "The Nature of Salience: An Experimental Investigation of Pure Coordination Games," American Economic Review, 84, 1994, 658 - 673.

Mitzkewitz, M., and Nagel, Rosemarie, "Experimental Results on Ultimatum Games with Incomplete Information," International Journal of Game Theory, 22, 1993, 171-198.

Mullin, Charles, and Reiley, David, "Recombinant Estimation for Normal-Form Games, with Applications to Auctions and Bargaining," Games and Economic Behavior, 2004, forthcoming.

Ortmann, Andreas, and Tichy, Lisa K., "Gender Differences in the Laboratory: Evidence from Prisoner's Dilemma Games,” Journal of Economic Behavior \& Organization, 39, 1999, 327-339.

Palfrey, Thomas R., and Prisbey, Jeffrey E., "Anomalous Behavior in Public Goods Experiments: How Much and Why?” American Economic Review, 87(5), December 1997, 829-846.

Small, Deborah A., and Loewenstein, George A., "Helping a Victim or Helping the Victim: Altruism and Identifiability," Journal of Risk \& Uncertainty, 26(1), 2003, 5-16.

Sonnemans, Joep; Schram, Arthur, and Offerman, Theo, "Public Goods Provision and Public Bad Prevention: The Effect of Framing," Journal of Economic Behavior \& Organization, 34, 1998, 143-161.

Tucker, A.W., “A Two-Person Dilemma,” Unpublished Manuscript, Stanford University, May 1950; published in UMAP Journal, 1, 1980, 101.

Whittington, Dale, "Improving the Performance of Contingent Valuation Studies in Developing Countries," Environmental and Resource Economics, 22(1-2), June 2002, 323-367. 


\section{Appendix A: Experimental Instructions (NOT FOR PUBLICATION) \\ WELCOME TO THE EXPERIMENT}

This is an experiment in the economics of decision making. Your participation in this experiment is voluntary. However, we think you will find the experiment interesting. You will be paid $\$ 10$ at the end of the experiment for your participation, and you might also earn money throughout different parts of the experiment. Please be careful to respect the privacy of other participants during the experiment, and refrain from interacting with them.

Before proceeding with tasks for which you will be paid additional money, we first need to collect some basic information about you. Please take a few moments to fill out the blue form. Your answers to these questions will be kept confidential, and will be used for statistical purposes only. We will be using the attached identification number to keep track of who answered which questions, but we will not be identifying your responses with your SSN or your name.

You should raise your hand when you are finished with this form so that the assistants can collect it. Once all the forms have been collected, we will proceed with the rest of the experiment. We will wait for everyone to have time to finish each task, so there is no need to hurry. 


\section{Some Questions About You}

ID

In this survey most of the questions asked are descriptive. We will not be grading your answers and your responses are completely confidential. Please think carefully about each question and give your best answers.

1. What is your AGE? years

2. What is your sex? (Circle one number.)

01 Male

02 Female

3. Which of the following categories best describes you? (Circle one number.)

01 White 06 Hispanic-American

02 African-American 07 Hispanic

03 African 08 Mixed Race

04 Asian-American 09 Other

05 Asian

4. What is your major? (Circle one number.)

01 Accounting

02 Economics

03 Finance

04 Business Administration, other than Accounting, Economics, or Finance

05 Education

06 Engineering

07 Health Professions

08 Public Affairs or Social Services

09 Biological Sciences

10 Math, Computer Sciences, or Physical Sciences

11 Social Sciences or History

12 Humanities

13 Psychology

14 Other Fields 
5. What is your class standing? (Circle one number.)

$\begin{array}{llll}01 & \text { Freshman } & 04 & \text { Senior } \\ 02 & \text { Sophomore } & 05 & \text { Masters } \\ 03 & \text { Junior } & 06 & \text { Doctoral }\end{array}$

6. What is the highest level of education you expect to complete? (Circle one number)

01 Bachelor's degree

02 Master's degree

03 Doctoral degree

04 First professional degree

7. What was the highest level of education that your father (or male guardian) completed? (Circle one number)

01 Less than high school

02 GED or High School Equivalency

03 High school

04 Vocational or trade school

05 College or university

06 Post Graduate

8. What was the highest level of education that your mother (or female guardian) completed? (Circle one number)

01 Less than high school

02 GED or High School Equivalency

03 High School

04 Vocational or trade school

05 College or university

06 Post Graduate

9. What is your citizenship status in the United States? (Circle one number.)

01 U.S. Citizen

02 Resident Alien

03 Non-Resident Alien

04 Other Status 
10. Are you a foreign student on a Student Visa? (Circle one number.)

01 Yes

02 No

11. Are you currently... (Circle one number.)

01 Single and never married?

02 Married?

03 Separated, divorced or widowed?

12. On a 4-point scale, what is your current GPA if you are doing a Bachelor's degree, or what was it when you did a Bachelor's degree? This GPA should refer to all of your coursework, not just the current year. (Circle one number:)

01 Between 3.75 and 4.0 GPA (mostly A's)

02 Between 3.25 and 3.74 GPA (about half A's and half B's)

03 Between 2.75 and 3.24 GPA (mostly B's)

04 Between 2.25 and 2.74 GPA (about half B's and half C's)

05 Between 1.75 and 2.24 GPA (mostly C's)

06 Between 1.25 and 1.74 GPA (about half C's and half D's)

07 Less than 1.25 (mostly D's or below)

08 Have not taken courses for which grades are given.

13. How many people live in your household? Include yourself, your spouse and any dependents. Do not include your parents or roommates unless you claim them as dependents.

14. Please circle the category below that describes the total amount of INCOME earned in 2003 by the people in your household (as "household" is defined in question 13). [Consider all forms of income, including salaries, tips, interest and dividend payments, scholarship support, student loans, parental support, social security, alimony, child support, and others.) (Circle one number.)

$01 \$ 15,000$ or under

$02 \$ 15,001-\$ 25,000$

$03 \$ 25,001-\$ 35,000$

$04 \$ 35,001-\$ 50,000$

$05 \$ 50,001-\$ 65,000$

$06 \$ 65,001-\$ 80,000$

$07 \$ 80,001-\$ 100,000$

08 over $\$ 100,000$ 
15. Please circle the category below that describes the total amount of INCOME earned in 2003 by your parents. [Consider all forms of income, including salaries, tips, interest and dividend payments, social security, alimony, child support, and others.] (Circle one number.)
$01 \$ 15,000$ or under
$02 \$ 15,001-\$ 25,000$
$03 \$ 25,001-\$ 35,000$
$04 \$ 35,001-\$ 50,000$
$05 \$ 50,001-\$ 65,000$
$06 \$ 65,001-\$ 80,000$
$07 \$ 80,001-\$ 100,000$
08 over $\$ 100,000$
09 Don't Know

16. Do you work part-time, full-time, or neither? (Circle one number.)
01 Part-time
02 Full-time
03 Neither

17. Before taxes, what do you get paid? (fill in only one)

$\begin{array}{ll}01 & \text { per hour before taxes } \\ 02 & \text { per week before taxes } \\ 03 & \text { per month before taxes } \\ 04 & \text { per year before taxes } \\ 05 & \text { not applicable }\end{array}$

18. Do you currently smoke cigarettes? (Circle one number.)

$\begin{array}{ll}01 & \text { Yes } \\ 02 & \text { No }\end{array}$

If yes, approximately how much do you smoke in one day? packs

18b. Who was the lecturer in the class that you were in when you signed up for this experiment? (Circle on number.)

01 Arthur Gilbert

02 George Potts

03 Paul Colomy

04 Terrency Toy

05 Sheldon York

06 Michael Monahan
07 Laurie Johnson

$08 \quad$ Irvin Jones

09 Keith Miller

10 Tracy Ehlers

11 None of the above, or cannot recall 
For the remaining questions, please select the one response that best matches your reaction to the statement.

19. "I believe that fate will mostly control what happens to me in the years ahead."

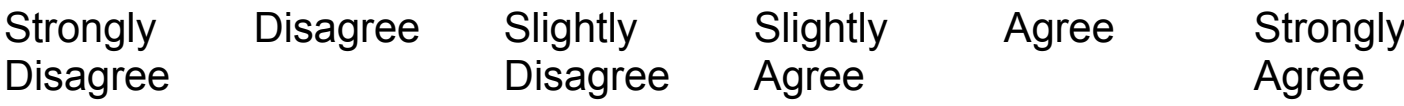

20. "I am usually able to protect my personal interests."

\begin{tabular}{|c|c|c|c|}
\hline $\begin{array}{l}\text { Strongly } \\
\text { Disagree }\end{array}$ & Disagree & $\begin{array}{l}\text { Slightly } \\
\text { Disagree }\end{array}$ & $\begin{array}{l}\text { Slightly } \\
\text { Agree }\end{array}$ \\
\hline
\end{tabular}

21. "When I get what I want, it's usually because I'm lucky."

Strongly Disagree Slightly Slightly Agree Strongly Disagree Disagree Agree Agree

22. "In order to have my plans work, I make sure that they fit in with the desires of people who have power over me."

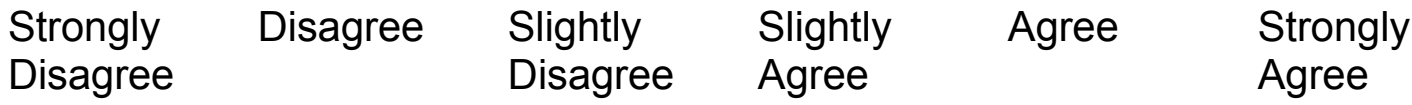

23. "I have mostly determined what has happened to me in my life so far."

\begin{tabular}{|c|c|c|c|c|}
\hline $\begin{array}{l}\text { Strongly } \\
\text { Disagree }\end{array}$ & Disagree & $\begin{array}{l}\text { Slightly } \\
\text { Disagree }\end{array}$ & $\begin{array}{l}\text { Slightly } \\
\text { Agree }\end{array}$ & Agree \\
\hline
\end{tabular}

24. "Whether or not I get into a car accident depends mostly on the other drivers."

\begin{tabular}{|c|c|c|c|}
\hline $\begin{array}{l}\text { Strongly } \\
\text { Disagree }\end{array}$ & Disagree & $\begin{array}{l}\text { Slightly } \\
\text { Disagree }\end{array}$ & $\begin{array}{l}\text { Slightly } \\
\text { Agree }\end{array}$ \\
\hline
\end{tabular}


25. "Chance occurrences determined most of the important events in my past."

Strongly Disagree Slightly Slightly Agree Strongly Disagree Disagree Agree Agree

26. "I feel like other people will mostly determine what happens to me in the future."

Strongly Disagree Slightly Slightly Agree Strongly

Disagree Disagree Agree Agree

27. "When I make plans, I am almost certain to make them work."

\begin{tabular}{|c|c|c|c|c|}
\hline $\begin{array}{l}\text { Strongly } \\
\text { Disagree }\end{array}$ & $\mathrm{Dis}$ & $\begin{array}{l}\text { Slightly } \\
\text { Disagree }\end{array}$ & $\begin{array}{l}\text { Slightly } \\
\text { Agree }\end{array}$ & Agree \\
\hline
\end{tabular}

28. "Getting what I want requires pleasing those people above me."

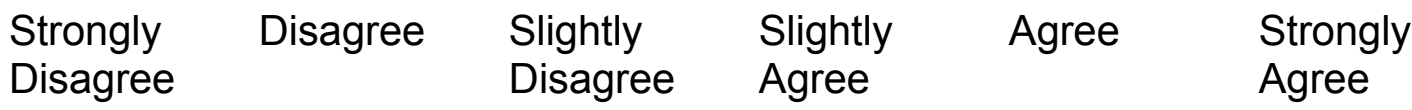

29. "Whether or not I get into a car accident depends mostly on how good a driver I am."

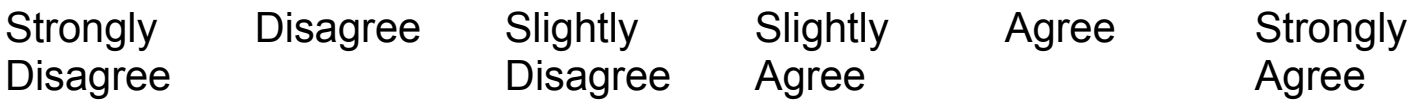

30. "Often there is no chance of protecting my personal interests from bad luck."

\begin{tabular}{|c|c|c|c|c|}
\hline $\begin{array}{l}\text { Strongly } \\
\text { Disagree }\end{array}$ & Disagree & $\begin{array}{l}\text { Slightly } \\
\text { Disagree }\end{array}$ & $\begin{array}{l}\text { Slightly } \\
\text { Agree }\end{array}$ & Agree \\
\hline
\end{tabular}


31. "When I get what I want, it's usually because I worked hard for it."
Strongly
Disagree
Slightly
Slightly
Disagree
Agree
Agree
Strongly
Disagree
Agree

Disagree

A

32. "Most of my personal history was controlled by other people who had power over me."

\begin{tabular}{|c|c|c|c|c|}
\hline $\begin{array}{l}\text { Strongly } \\
\text { Disagree }\end{array}$ & Disagree & $\begin{array}{l}\text { Slightly } \\
\text { Disagree }\end{array}$ & $\begin{array}{l}\text { Slightly } \\
\text { Agree }\end{array}$ & Agree \\
\hline
\end{tabular}

33. "Whether or not I get into a car accident is mostly a matter of luck."

\begin{tabular}{|c|c|c|c|c|}
\hline $\begin{array}{l}\text { Strongly } \\
\text { Disagree }\end{array}$ & Disagree & $\begin{array}{l}\text { Slightly } \\
\text { Disagree }\end{array}$ & $\begin{array}{l}\text { Slightly } \\
\text { Agree }\end{array}$ & Agree \\
\hline
\end{tabular}

34. "I think that I will mostly control what happens to me in future years."
Strongly
Disagree
Slightly
Slightly
Disagree
Agree
Agree
Strongly
Agree

35. "People like myself have very little chance of protecting our personal interests when they conflict with those of strong pressure groups."

\begin{tabular}{|c|c|c|c|c|}
\hline $\begin{array}{l}\text { Strongly } \\
\text { Disagree }\end{array}$ & Disagree & $\begin{array}{l}\text { Slightly } \\
\text { Disagree }\end{array}$ & $\begin{array}{l}\text { Slightly } \\
\text { Agree }\end{array}$ & Agree \\
\hline
\end{tabular}

36. "It's not always wise for me to plan too far ahead because many things turn out to be a matter of good or bad fortune."

\begin{tabular}{|c|c|c|c|c|}
\hline $\begin{array}{l}\text { Strongly } \\
\text { Disagree }\end{array}$ & Disagree & $\begin{array}{l}\text { Slightly } \\
\text { Disagree }\end{array}$ & $\begin{array}{l}\text { Slightly } \\
\text { Agree }\end{array}$ & Agree \\
\hline
\end{tabular}


$\mathrm{O}, \mathrm{OC}$

At the beginning of the experiment you selected an ID number by picking an envelope from us. Would those of you that selected an odd ID number please proceed to a separate room? You will undertake the rest of the experiment there, with the experimenter that is going with you. Thank you! The rest of you should remain here. 
In this experiment you are asked to make a series of choices about how to divide points between yourself and one other subject in the other room. You and the other subject will be paired randomly and you will not be told each other's identity.

As you divide the points, you and the other subject will each earn money. Every point that you earn will be worth 10,20,30 or 40 cents, depending on the choice. For example, if your points are worth 10 cents each and you earn 58 points you will make $\$ 5.80$ for that choice. Similarly for the earnings of the other player.

Each choice you make is similar to the following:

\section{Divide 50 points: Hold}

@ \$0.10 each, and Pass

@ \$0.20 each.

In this choice you must divide 50 points. You can keep all of the points, keep some and pass some, or pass all of the points. In this example, you will receive 10 cents for every point you hold, and the other player will receive 20 cents for every point you pass. For example, if you hold 50 and pass 0 points, you will receive $50 \times \$ 0.10=\$ 5.00$, and the other player will receive no points and $\$ 0$. If you hold 0 and pass 50 points, you will receive no points and $\$ 0$, and the other player will receive $50 \times \$ 0.20=\$ 10.00$.

However, you could choose any number between 0 and 50 to hold. For instance, you could choose to hold 29 tokens and pass 21 . In this case you would earn 29 points, or $29 \times \$ 0.10=\$ 2.90$, and the other subject would receive $21 \times \$ 0.20=\$ 4.20$.

Here is another example:

Divide 50 points: Hold @ \$0.30 each, and Pass @ \$0.30 each.

In this example every point you hold earns you 30 cents, and every point you pass earns the other subject 30 cents.

Important Note: In all cases you can choose any number to hold and any number to pass, but the number of points you hold plus the number of points you pass must equal the total number of points to divide.

We will select one of your decisions to actually implement at the end of the session. We have allowed for up to $\$ 32$ to be paid out for the decision that is selected, multiplied by the number of pairs of subjects here today. This is the maximum amount that can be paid out, depending on your choices and the roll of the die selecting the decision to be implemented. Depending on your choices, and the decision picked to be implemented, we might not need to pay out as much as $\$ 32$ per pair.

Please do not talk. Are there any questions? 
In this experiment you are asked to make a series of choices about how to divide points between yourself and a public charity. The name and address of the charity is in a sealed envelope which we will open at the end of the session. We will write a check to the charity at the end of the session, seal it in an envelope, and you can come with us to the nearest public mailbox to see it mailed.

As you divide the points, you and the charity will each earn money. Every point that you earn will be worth 10, 20, 30 or 40 cents, depending on the choice. For example, if your points are worth 10 cents each and you earn 58 points you will make $\$ 5.80$ for that choice. Similarly for the earnings of the charity.

Each choice you make is similar to the following:

Divide 50 points: Hold @ \$0.10 each, and Pass @ \$0.20 each.

In this choice you must divide 50 points. You can keep all of the points, keep some and pass some, or pass all of the points. In this example, you will receive 10 cents for every point you hold, and the charity will receive 20 cents for every point you pass. For example, if you hold 50 and pass 0 points, you will receive $50 \times \$ 0.10=\$ 5.00$, and the charity will receive no points and $\$ 0$. If you hold 0 and pass 50 points, you will receive no points and $\$ 0$, and the charity will receive $50 \times \$ 0.20=\$ 10.00$. However, you could choose any number between 0 and 50 to hold. For instance, you could choose to hold 29 tokens and pass 21 . In this case you would earn 29 points, or $29 \times \$ 0.10=\$ 2.90$, and the charity would receive $21 \times \$ 0.20=\$ 4.20$.

Here is another example:

Divide 50 points: Hold @ \$0.30 each, and Pass @ \$0.30 each.

In this example every point you hold earns you 30 cents, and every point you pass earns the charity 30 cents.

Important Note: In all cases you can choose any number to hold and any number to pass, but the number of points you hold plus the number of points you pass must equal the total number of points to divide.

We will select one of your decisions to actually implement at the end of the session. We have allowed for up to $\$ 32$ to be paid out for the decision that is selected, multiplied by the number of subjects here today. This is the maximum amount that can be paid out, depending on your choices and the roll of the die selecting the decision to be implemented. Depending on your choices, and the decision picked to be implemented, we might not need to pay out as much as $\$ 32$ per pair.

Please do not talk. Are there any questions? 
OC

In this experiment you are asked to make a series of choices about how to divide points between yourself and one other subject in the other room. You and the other subject will be paired randomly and you will not be told each other's identity.

As you divide the points, you and the other subject will each earn money. Every point that you earn will be worth $10,20,30$ or 40 cents, depending on the choice. For example, if your points are worth 10 cents each and you earn 58 points you will make $\$ 5.80$ for that choice. Similarly for the earnings of the other player.

Each choice you make is similar to the following:

Divide 50 points: Hold

@ \$0.10 each, and Pass
@ \$0.20 each.

In this choice you must divide 50 points. You can keep all of the points, keep some and pass some, or pass all of the points. In this example, you will receive 10 cents for every point you hold, and the other player will receive 20 cents for every point you pass. For example, if you hold 50 and pass 0 points, you will receive $50 \times \$ 0.10=\$ 5.00$, and the other player will receive no points and $\$ 0$. If you hold 0 and pass 50 points, you will receive no points and $\$ 0$, and the other player will receive $50 \times \$ 0.20=\$ 10.00$. However, you could choose any number between 0 and 50 to hold. For instance, you could choose to hold 29 tokens and pass 21 . In this case you would earn 29 points, or $29 \times \$ 0.10=\$ 2.90$, and the other subject would receive $21 \times \$ 0.20=\$ 4.20$.

Here is another example:

Divide 50 points: Hold @ \$0.30 each, and Pass @ \$0.30 each.

In this example every point you hold earns you 30 cents, and every point you pass earns the other subject 30 cents.

Important Note: In all cases you can choose any number to hold and any number to pass, but the number of points you hold plus the number of points you pass must equal the total number of points to divide.

We will select one of your decisions to actually implement at the end of the session. We have allowed for up to $\$ 32$ to be paid out for the decision that is selected, multiplied by the number of pairs of subjects here today. This is the maximum amount that can be paid out, depending on your choices and the roll of the die selecting the decision to be implemented. Depending on your choices, and the decision picked to be implemented, we might not need to pay out as much as $\$ 32$ per pair. Any monies left will be paid to a public charity. The name and address of the charity is in a sealed envelope which we will open at the end of the session. We will write a check to the charity at the end of the session, seal it in an envelope, and you can come with us to the nearest public mailbox to see it mailed.

Please do not talk. Are there any questions? 
In this experiment you are asked to make a series of choices about how to divide points between yourself and a public charity. The name and address of the charity is in a sealed envelope which we will open at the end of the session. We will write a check to the charity at the end of the session, seal it in an envelope, and you can come with us to the nearest public mailbox to see it mailed.

As you divide the points, you and the charity will each earn money. Every point that you earn will be worth 10, 20, 30 or 40 cents, depending on the choice. For example, if your points are worth 10 cents each and you earn 58 points you will make $\$ 5.80$ for that choice. Similarly for the earnings of the charity.

Each choice you make is similar to the following:

Divide 50 points: Hold @ \$0.10 each, and Pass @ \$0.20 each.

In this choice you must divide 50 points. You can keep all of the points, keep some and pass some, or pass all of the points. In this example, you will receive 10 cents for every point you hold, and the charity will receive 20 cents for every point you pass. For example, if you hold 50 and pass 0 points, you will receive $50 \times \$ 0.10=\$ 5.00$, and the charity will receive no points and $\$ 0$. If you hold 0 and pass 50 points, you will receive no points and $\$ 0$, and the charity will receive $50 \times \$ 0.20=\$ 10.00$. However, you could choose any number between 0 and 50 to hold. For instance, you could choose to hold 29 tokens and pass 21 . In this case you would earn 29 points, or $29 \times \$ 0.10=\$ 2.90$, and the charity would receive $21 \times \$ 0.20=\$ 4.20$.

Here is another example:

Divide 50 points: Hold @ \$0.30 each, and Pass @ \$0.30 each.

In this example every point you hold earns you 30 cents, and every point you pass earns the charity 30 cents.

Important Note: In all cases you can choose any number to hold and any number to pass, but the number of points you hold plus the number of points you pass must equal the total number of points to divide.

We will select one of your decisions to actually implement at the end of the session. We have allowed for up to $\$ 32$ to be paid out for the decision that is selected, multiplied by the number of subjects here today. This is the maximum amount that can be paid out, depending on your choices and the roll of the die selecting the decision to be implemented. Depending on your choices, and the decision picked to be implemented, we might not need to pay out as much as $\$ 32$ per pair. Any monies left will be paid to one other subject in the room, selected at random.

Please do not talk. Are there any questions? 
$\mathrm{P}-\mathrm{O}$ and $\mathrm{OC}$

In this experiment we are going to ask you to predict the choices of the people in the other room. In a moment we will show you the instructions that they are being asked to follow. They will make 10 choices, as explained in the instructions we will give you. You should write down on the Decision Sheet your prediction of the average response to each choice from all of the people in the other room. In other words, for choice \#1, write down what you predict the average response will be. Similarly for choices 2 through 10.

You will be rewarded based on your accuracy. As the instructions will explain, one of these 10 choices will be picked at random for implementation, and we will use that choice to decide who was the most accurate at predicting the choices made in the other room.

The person that predicts the average response most accurately will receive $\$ 20$, and the three people that predict the average response best after that person will each receive $\$ 10$. In the event of a tie, we will toss coins to see who gets the rewards. So the best four predictions will get a reward.

These rewards are in addition to any money you may receive from the decisions of the people in the other room.

The subjects in the other room do not know that you are being paid to predict their responses.

Please do not talk between yourselves. Here are the instructions given to the subjects in the other room. Please read them quietly, and write down your predictions. Do you have any questions? 
ID: A

\section{Decision Form}

Directions: Please fill in the blanks below. Make sure that the amount of points listed under Hold plus the number listed under Pass equals the total number of points available. At the end of the experiment we will pick one of these decisions at random to actually implement.

1. Divide 75 points: Hold

@ \$0.20 each, and Pass

@ \$0.40 each.

2. Divide 40 points: Hold @ \$0.20 each, and Pass @ \$0.60 each.

3. Divide 75 points: Hold @ \$0.20 each, and Pass @ \$0.20 each.

4. Divide 60 points: Hold @ \$0.20 each, and Pass @ \$0.40 each.

5. Divide 40 points: Hold @ \$0.50 each, and Pass @ \$0.50 each.

6. Divide 100 points: Hold @ \$0.10 each, and Pass @ \$0.20 each.

7. Divide 60 points: Hold @ \$0.20 each, and Pass @ \$0.30 each.

8. Divide 80 points: Hold @ \$0.20 each, and Pass @ \$0.40 each.

9. Divide 40 points: Hold @ \$0.20 each, and Pass @ \$0.50 each. 10. Divide 40 points: Hold @ \$0.20 each, and Pass @ \$0.80 each. 
ID: B

\section{Decision Form}

Directions: Please fill in the blanks below. Make sure that the amount of points listed under Hold plus the number listed under Pass equals the total number of points available. At the end of the experiment we will pick one of these decisions at random to actually implement.

1. Divide 40 points: Hold

@ \$0.20 each, and Pass

@ \$0.80 each.

2. Divide 40 points: Hold @ \$0.20 each, and Pass @ \$0.50 each.

3. Divide 80 points: Hold @ \$0.20 each, and Pass @ \$0.40 each.

4. Divide 40 points: Hold @ \$0.50 each, and Pass @ \$0.50 each.

5. Divide 60 points: Hold @ \$0.20 each, and Pass @ \$0.30 each.

6. Divide 100 points: Hold @ \$0.10 each, and Pass @ \$0.20 each.

7. Divide 60 points: Hold @ \$0.20 each, and Pass @ \$0.40 each.

8. Divide 75 points: Hold @ \$0.20 each, and Pass @ \$0.20 each.

9. Divide 40 points: Hold @ \$0.20 each, and Pass @ \$0.60 each. 10. Divide 75 points: Hold @ \$0.20 each, and Pass @ \$0.40 each. 
ID: C

\section{Decision Form}

Directions: Please fill in the blanks below. Make sure that the amount of points listed under Hold plus the number listed under Pass equals the total number of points available. At the end of the experiment we will pick one of these decisions at random to actually implement.

1. Divide 100 points: Hold

$@ \$ 0.10$ each, and Pass

@ \$0.20 each.

2. Divide 40 points: Hold @ \$0.20 each, and Pass @ \$0.60 each.

3. Divide 60 points: Hold @ \$0.20 each, and Pass @ \$0.30 each.

4. Divide 60 points: Hold @ \$0.20 each, and Pass @ \$0.40 each.

5. Divide 40 points: Hold @ \$0.20 each, and Pass @ \$0.50 each.

6. Divide 75 points: Hold @ \$0.20 each, and Pass @ \$0.40 each.

7. Divide 75 points: Hold @ \$0.20 each, and Pass @ \$0.20 each.

8. Divide 40 points: Hold @ \$0.20 each, and Pass @ \$0.80 each.

9. Divide 40 points: Hold @ \$0.50 each, and Pass @ \$0.50 each. 10. Divide 80 points: Hold @ \$0.20 each, and Pass @ \$0.40 each. 
ID: AP

\section{Decision Form}

Directions: Please fill in the blanks below. Make sure that the amount of points listed under Hold plus the number listed under Pass equals the total number of points available. You should write down what you think the average response in the other room will be to each decision.

1. Divide 75 points: Hold @ \$0.20 each, and Pass @ \$0.40 each.

2. Divide 40 points: Hold @ \$0.20 each, and Pass @ \$0.60 each.

3. Divide 75 points: Hold @ \$0.20 each, and Pass @ \$0.20 each.

4. Divide 60 points: Hold @ \$0.20 each, and Pass @ \$0.40 each.

5. Divide 40 points: Hold @ \$0.50 each, and Pass @ \$0.50 each.

6. Divide 100 points: Hold @ \$0.10 each, and Pass @ \$0.20 each.

7. Divide 60 points: Hold @ \$0.20 each, and Pass @ \$0.30 each.

8. Divide 80 points: Hold @ \$0.20 each, and Pass @ \$0.40 each.

9. Divide 40 points: Hold @ \$0.20 each, and Pass @ \$0.50 each. 10. Divide 40 points: Hold @ \$0.20 each, and Pass @ \$0.80 each. 
ID: BP

\section{Decision Form}

Directions: Please fill in the blanks below. Make sure that the amount of points listed under Hold plus the number listed under Pass equals the total number of points available. You should write down what you think the average response in the other room will be to each decision.

1. Divide 40 points: Hold @ \$0.20 each, and Pass @ \$0.80 each.

2. Divide 40 points: Hold @ \$0.20 each, and Pass @ \$0.50 each.

3. Divide 80 points: Hold @ \$0.20 each, and Pass @ \$0.40 each.

4. Divide 40 points: Hold @ \$0.50 each, and Pass @ \$0.50 each.

5. Divide 60 points: Hold @ \$0.20 each, and Pass @ \$0.30 each.

6. Divide 100 points: Hold @ \$0.10 each, and Pass @ \$0.20 each.

7. Divide 60 points: Hold @ \$0.20 each, and Pass @ \$0.40 each.

8. Divide 75 points: Hold @ \$0.20 each, and Pass @ \$0.20 each.

9. Divide 40 points: Hold @ \$0.20 each, and Pass @ \$0.60 each. 10. Divide 75 points: Hold @ \$0.20 each, and Pass @ \$0.40 each. 
ID: CP

\section{Decision Form}

Directions: Please fill in the blanks below. Make sure that the amount of points listed under Hold plus the number listed under Pass equals the total number of points available. You should write down what you think the average response in the other room will be to each decision.

1. Divide 100 points: Hold

$@ \$ 0.10$ each, and Pass

@ \$0.20 each.

2. Divide 40 points: Hold @ \$0.20 each, and Pass @ \$0.60 each.

3. Divide 60 points: Hold @ \$0.20 each, and Pass @ \$0.30 each.

4. Divide 60 points: Hold @ \$0.20 each, and Pass @ \$0.40 each.

5. Divide 40 points: Hold @ \$0.20 each, and Pass @ \$0.50 each.

6. Divide 75 points: Hold @ \$0.20 each, and Pass @ \$0.40 each.

7. Divide 75 points: Hold @ \$0.20 each, and Pass @ \$0.20 each.

8. Divide 40 points: Hold @ \$0.20 each, and Pass @ \$0.80 each.

9. Divide 40 points: Hold @ \$0.50 each, and Pass @ \$0.50 each. 10. Divide 80 points: Hold @ \$0.20 each, and Pass @ \$0.40 each. 


\section{Appendix B: Detailed Statistical Results (NOT FOR PUBLICATION)}

Figures A1 through A4 display box plots of the distribution of apparent pass rates for each treatment and return to giving. ${ }^{43}$ These plots reveal that the variations in apparent pass rates displayed in the text are primarily due to variations in one tail or the other of the distribution, rather than shifts in the whole distribution. This points to the possibility that some characteristic of the individual helps explain changes in altruism as the return to giving or the treatment changes. This is borne out by the statistical analysis reported in the text, and the estimation results reported below for each treatment. These estimates underlie the predictions in Figure 4.

Figure A5 displays a scatterplot of earnings for each player in each treatment. These earnings are denominated in dollars and cents. In general they indicate that subjects did not, as a whole, seek to equalize earnings, since the tendency is for the Dictator to get more in relation to the Peasant. However, within each scatterplot it is easy to see that some subjects may have been equalizing earnings, even if it is not the dominant tendency.

\section{Additional Reference}

Chambers, J.M.; Cleveland, W.S.; Kleiner, B., and Tukey, P.A., Graphical Methods for Data Analysis (Monterey, CA: Wadsworth, 1983).

\footnotetext{
43 A box plot shows the median line, then the interquartile range (the $25^{\text {th }}$ and $75^{\text {th }}$ percentiles) as a box, then the adjacent values as "whiskers," and then outlying observations as dots. See Chambers et al. [1983] for explanations of the box plot.
} 
Figure A1: Altruism in Treatment C

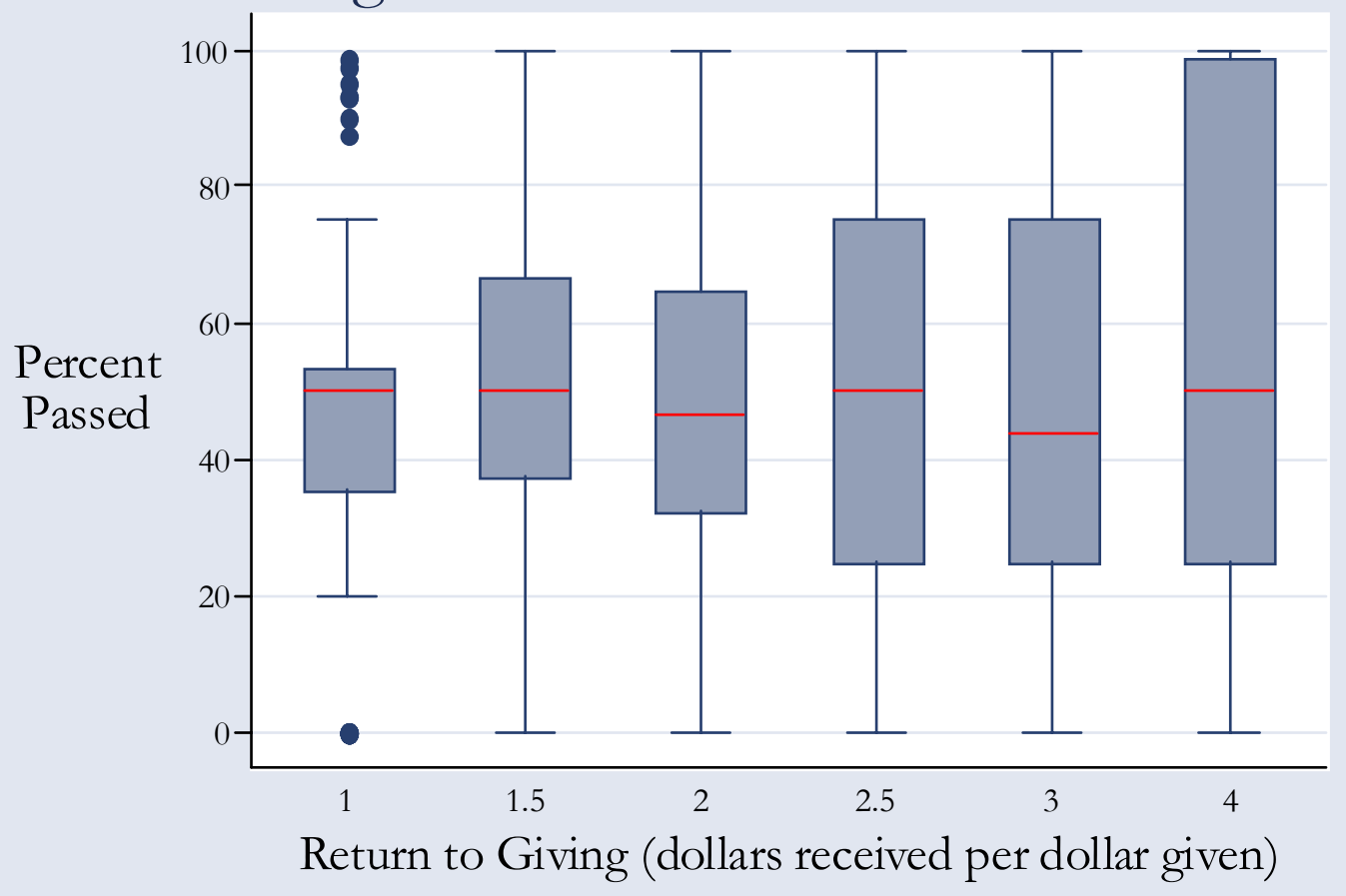

Figure A2: Altruism in Treatment $\mathrm{C}(\mathrm{O})$

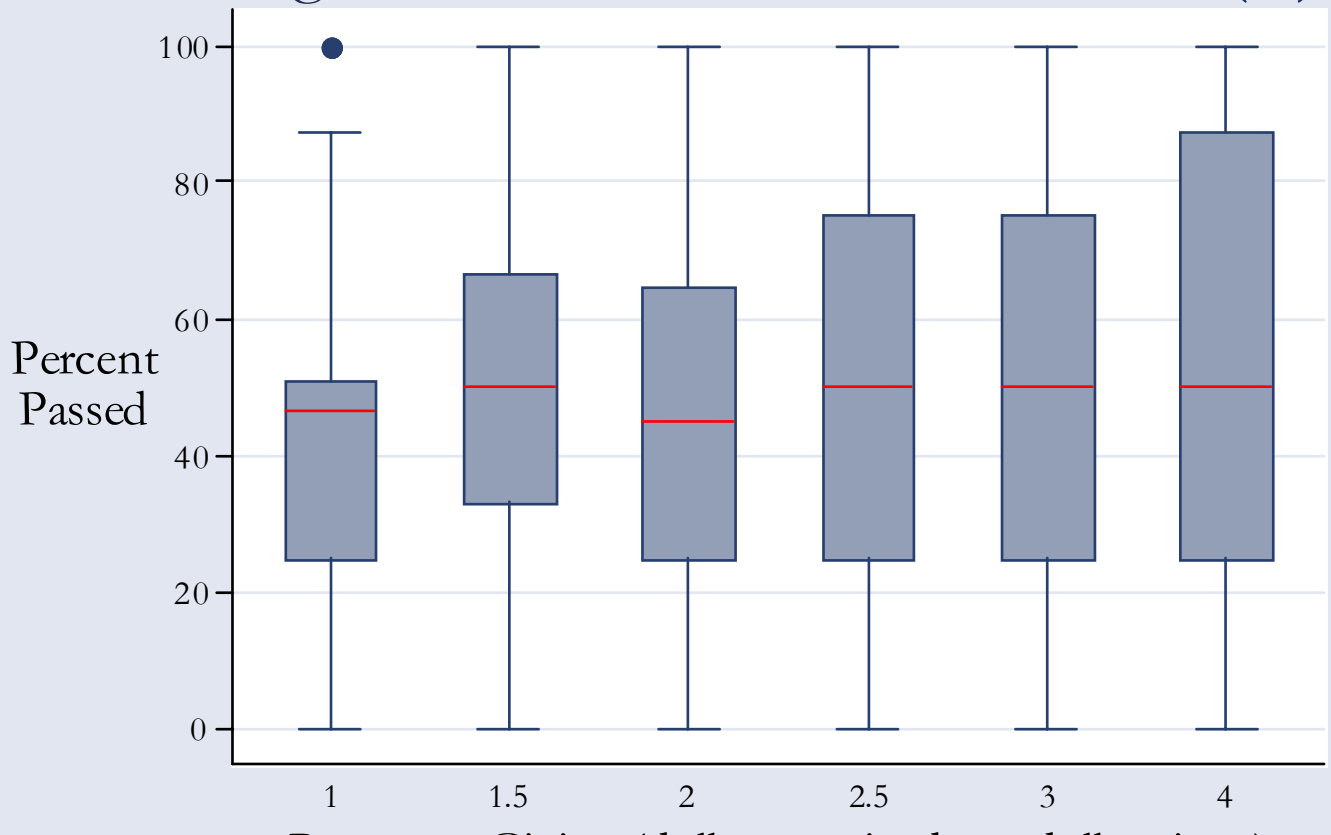

Return to Giving (dollars received per dollar given) 
Figure A3: Altruism in Treatment $\mathrm{O}$

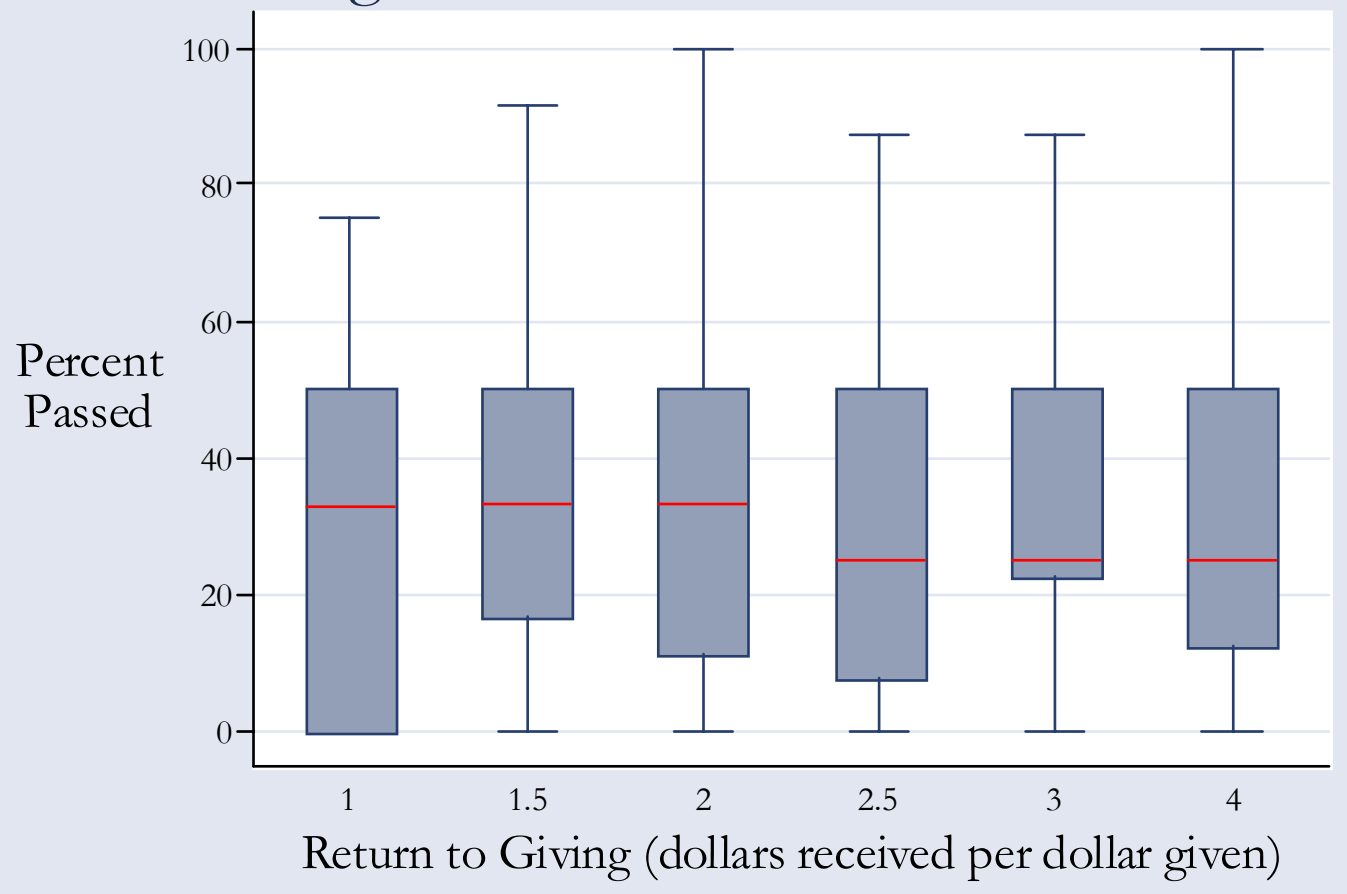

Figure A4: Altruism in Treatment $\mathrm{O}(\mathrm{C})$

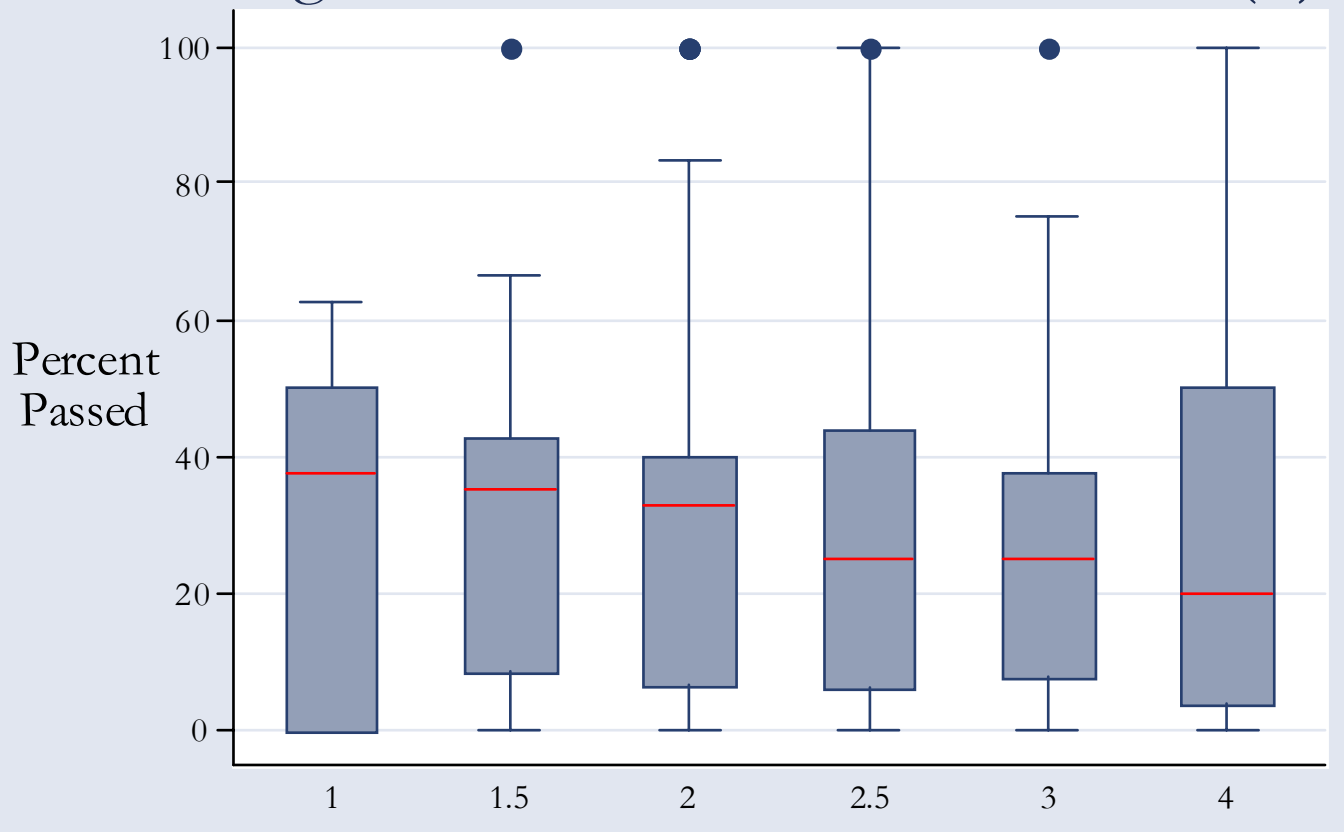

Return to Giving (dollars received per dollar given) 


\section{Figure A5: Scatterplots of Earnings}

Treatment C

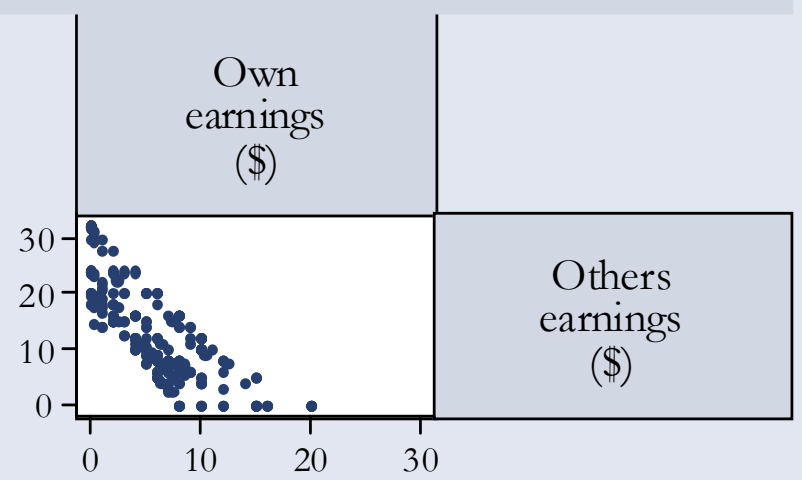

Treatment $\mathrm{O}$

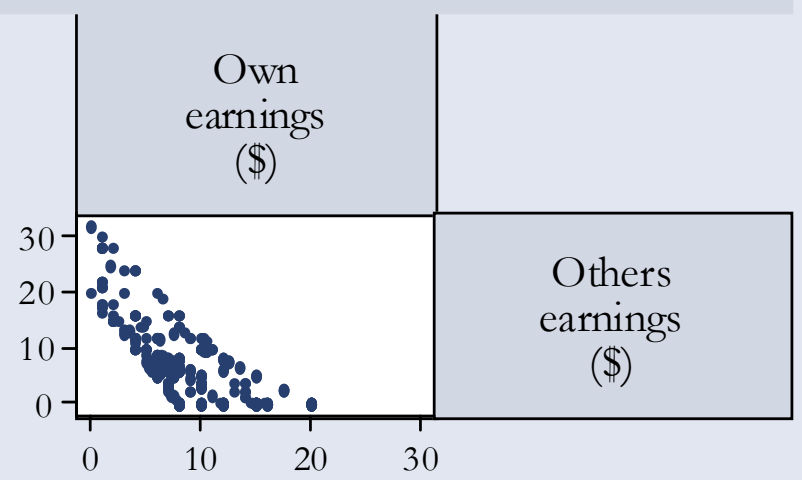

Treatment $\mathrm{C}(\mathrm{O})$

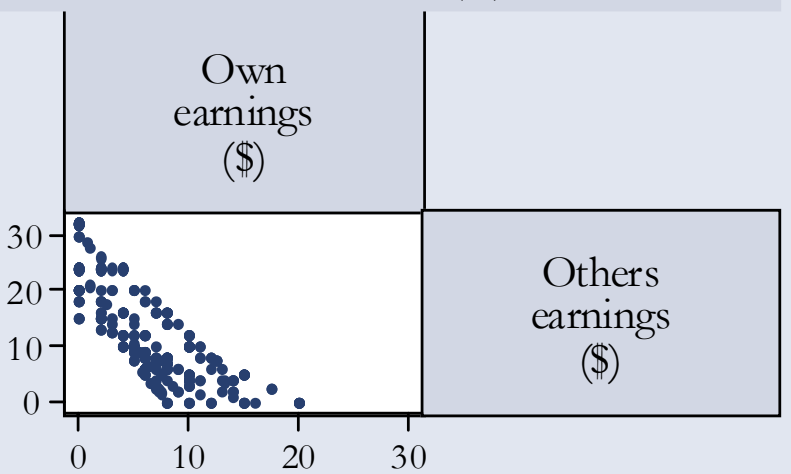

Treatment $\mathrm{O}(\mathrm{C})$

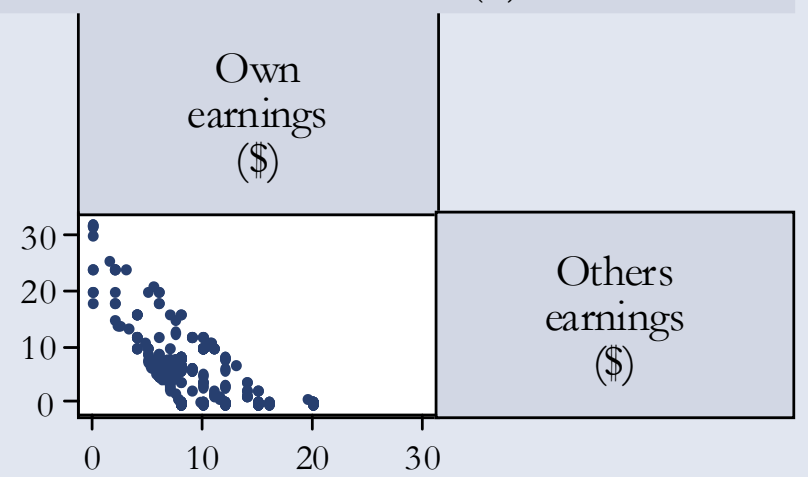

